\title{
Configuración microespacial de la industria en la Ciudad de México a inicios del siglo XXI*
}

\author{
Fermín Cruz** \\ Gustavo Garza***
}

La organización de la producción manufacturera en las grandes metrópolis se ha ido transformando por su relativa desindustrialización y acelerada servicialización, en mayor o menor medida según el grado de inserción en la nueva división internacional del trabajo. El objetivo principal de este artículo es determinar qué tipo de patrón industrial existía en el Área Metropolitana de la Ciudad de México en 2003, partiendo de los modelos conceptuales de la organización del espacio urbano más conocidos. Para lograrlo se realizó un análisis microespacial del producto interno bruto (PIB) de las manufacturas de 4418 áreas geoestadísticas básicas (AGEB), con lo cual ha sido posible identificar siete grandes concentraciones fabriles. A partir de ello se analizaron su morfología, su estructura espacial interna y su evolución futura. Un segundo gran objetivo es esquematizar la evolución de los siete polígonos industriales desde los años sesenta, lo que ha permitido inferir la relevancia de las condiciones generales de la producción como elemento determinante de la configuración industrial de la metrópoli.

Palabras clave: estructuración industrial metropolitana, modelos de estructura urbana, industrialización de la Ciudad de México.

Fecha de recepción: 3 de septiembre de 2012.

Fecha de aceptación: 20 de marzo de 2013.

Micro-Spatial Configuration of Industry in Mexico City in the Early $21^{\text {st }}$ Century

The organization of manufacturing production in the large metropolitan areas has been transformed by its relative de-industrialization and rapid service sector growth, to a greater or lesser extent depending on the degree of integration into the new international division of labor. The main objective of this paper is to determine the type of industrial pattern that existed in the Mexico City Metropolitan Area in 2003, based on the best-known conceptual models of the organization of urban space. To achieve this, a micro-spatial analysis of the

* Este artículo es una versión corregida del capítulo 5 de la tesis doctoral que Fermín Cruz presentó en junio de 2012 bajo la dirección de Gustavo Garza (Cruz, 2012).

** Investigador asociado en el proyecto "Estructuración intrametropolitana del sector servicios en la Ciudad de México, 1960-2008”, coordinado por Gustavo Garza en El Colegio de México. Correo electrónico: <fcruz@colmex.mx>.

*** Profesor investigador del Centro de Estudios Demográficos, Urbanos y Ambientales de El Colegio de México. Correo electrónico: <ggarza@colmex.mx>. 
gross domestic product (GDP) of the goods in 4418 basic geostatistical areas (BGA) was performed, which identified seven large manufacturing concentrations. This was used to analyze its morphology, internal spatial structure and future evolution. A second major objective is to outline the evolution of the seven industrial estates from the 1960s, which has made it possible to infer the importance of the general production conditions as a determinant of the industrial configuration of the metropolis.

Key words: metropolitan industrial structuring, urban structure models, industrialization of Mexico City.

El cuerpo teórico dominante en las investigaciones empíricas sobre la distribución de las actividades urbanas lo constituyen los modelos elaborados en Estados Unidos de América para describir sus ciudades. Se suele cuestionar la pertinencia de utilizar dichos esquemas espaciales como referencia metodológica para los estudios de ciudades latinoamericanas, no obstante que en sus orígenes todas las urbes tuvieron una estructura espacial similar de tipo monocéntrico.

Con el fin de contrastar la configuración espacial de las manufacturas en la Ciudad de México para determinar sus peculiaridades dentro de los postulados teóricos de la denominada "escuela de Chicago" y los modelos que se han desarrollado a partir de ella, el objetivo principal de este artículo es realizar un estudio sobre la distribución industrial en la Ciudad de México a escala microespacial, lo cual permitirá observar las singularidades de su patrón de localización en una escala geográfica muy detallada. El análisis correspondiente constituirá una visión pormenorizada de la organización manufacturera en el Área Metropolitana de la Ciudad de México (AMCM). ${ }^{1}$ Las unidades administrativas que conformaron la zona de estudio fueron las 16 delegaciones del Distrito Federal y 15 municipios conurbados del Estado de México. ${ }^{2}$ Se estudiará la distribución territorial de la actividad in-

${ }^{1}$ El Área Metropolitana de la Ciudad de México (AMCM), técnicamente hablando es el tejido construido de la urbe que se inicia en el centro de la ciudad, en el Zócalo, y se extiende sin interrupción hacia todos los puntos cardinales. La Zona Metropolitana de la Ciudad de México (ZMCM) sería su envolvente, constituida por las delegaciones y municipios que están total o parcialmente cubiertos por dicha mancha urbana (Unikel, Ruiz y Garza, 1976: 116-119). En este artículo se utilizará el primer concepto, pero por razones de estilo se mencionará indistintamente Ciudad de México o AMCM para referirse siempre a esta última.

${ }^{2}$ Los municipios que conformaron el AMCM fueron: 1) Atizapán de Zaragoza, 2) Coacalco, 3) Cuautitlán, 4) Cuautitlán Izcalli, 5) Chalco, 6) Ecatepec, 7) Huixquilucan, 8) Ixtapaluca, 9) La Paz, 10) Naucalpan, 11) Netzahualcóyotl, 12) Tlalnepantla de Baz, 13) Tepotzotlán, 14) Tultitlán y 15) Valle de Chalco Solidaridad. Ésta es una versión 
dustrial para 2003 mediante el uso de las unidades geográficas censales más pequeñas: las áreas geoestadísticas básicas (AGEB), según han sido delimitadas por el Instituto Nacional de Estadística y Geografía (INEGI). Antes de ello, como un segundo objetivo, se presenta en un primer acápite una síntesis de los principales modelos de estructuración del espacio urbano y, más específicamente, sus adecuaciones a las ciudades de América Latina. Finalmente, en el último inciso, como tercer propósito, se esquematiza la evolución de los polígonos industriales identificados con la intención de evidenciar la necesidad de realizar un análisis histórico-estructural de la organización de las actividades económicas en las urbes, donde la categoría de las condiciones generales de la producción (infraestructuras y equipamiento urbano) sea la variable explicativa central.

Para alcanzar el objetivo principal fue necesario realizar una serie de labores técnicas para determinar las variables a utilizar y la delimitación del área de estudio. Las diversas investigaciones empíricas que analizan la distribución de las actividades económicas en el interior de las ciudades recurren básicamente a cuatro variables: el número de establecimientos, la superficie, el personal ocupado y el valor de la producción. Por ejemplo, Duranton y Overman (2006) consideran a los establecimientos como variable para medir los patrones de la actividad industrial en algunas ciudades de Estados Unidos, aunque refinan el análisis por el tamaño de dichos establecimientos según el personal ocupado por unidad económica. Por otro lado, Escolano y Ortiz (2005) analizan la organización espacial de la actividad comercial en el Gran Santiago de Chile, considerando el uso de suelo como variable para medir la intensidad de la actividad en el espacio. Algunos estudios efectuados para la Ciudad de México utilizan igualmente dichas variables para medir la actividad económica intrametropolitana. Garza y Sobrino (2000) emplean el producto sectorial, mientras que Sobrino (2006), así como Aguilar y Alvarado (2004), el personal ocupado.

Considerando que tanto los establecimientos como el personal ocupado ocultan las diferencias de la productividad total de los factores de la producción, en este artículo se optó por utilizar el producto interno bruto (PIB) como el indicador que mejor representa al proceso de producción que engloba la mano de obra y el capital, por lo que

compacta del AMCM, dado que ella comprende el 98.65\% del PIB industrial de su delimitación completa de 40 municipios mexiquenses y Tizayuca, Hidalgo. Se simplifica el análisis espacial, pero se incluye prácticamente todo el producto manufacturero. 
se considera la opción más adecuada para medir la actividad económica con un solo indicador.

Específicamente, la variable a emplear en este artículo será el "valor agregado censal bruto" (VACB), definido como "el valor de la producción que se añade durante el proceso de trabajo, por la actividad creadora y de transformación del personal ocupado, el capital y la organización ejercida sobre los materiales que se consumen en la realización de la actividad económica” (INEGI, 2004: 42). El vACB de los censos económicos es conceptualmente equivalente al PIB de las Cuentas Nacionales, por lo que en adelante se entenderán como sinónimos, si bien se prefiere mencionar a este último por ser generalmente más utilizado y comprendido.

La fuente de información fue el XVI Censo industrial de 2004, el cual recaba datos referidos a 2003. La principal limitación de la fuente de información es que no considera aquellas actividades manufactureras que son realizadas en las viviendas o que no se desarrollan en espacios fijos, excluyendo por tanto la producción manufacturera informal. Los datos se refieren, por ende, a las actividades industriales que se ejecutan en la economía formal, esto es, en negocios establecidos con una dirección postal bien identificada.

La información censal fue depurada, eliminando sectores como la minería, la generación de electricidad, agua y suministro de gas por ductos, así como la construcción. Se descartaron estas actividades, además, debido a su baja aportación a la producción total de la AMCM. ${ }^{3}$ La construcción también se descartó porque no tiene localización fija, es decir, una constructora no realiza la actividad económica en su establecimiento, sino en predios ajenos, sesgando así la información de localización. Por lo tanto, solamente se analizaron las manufacturas, principal actividad industrial en la ciudad. Entendiendo que se han suprimido los sectores previamente mencionados, a lo largo de la investigación se utilizan indistintamente los términos "industria" y "manufactura" como sinónimos.

En 2003 la zona de estudio abarcaba un área de $1563 \mathrm{~km}^{2}$ y se conformaba solamente por las AGEB urbanas con una actividad industrial de cierta significación. Esto permitió discriminar áreas periféricas que por su baja integración a la urbe y limitada industrialización tienen muy pocos establecimientos (menos de 3). En estos casos los censos no presentan la información por las leyes de confidencialidad censal, en 2003.

${ }^{3}$ La industria manufacturera aportó $76 \%$ del total del PIB industrial de la ZMCM 
o porque la producción es tan baja que indica un nulo PIB manufacturero. ${ }^{4}$ Esta delimitación más detallada permite descartar las actividades industriales marginales que se realizan en el interior de los municipios conurbados pero que no forman parte contigua al tejido urbano de la ciudad. Con el gran potencial del estudio microespacial, en este trabajo fue posible realizar una delimitación muy detallada de las concentraciones industriales en el interior de la metrópoli, definiéndolas a partir de su morfología e intensidad de producción. En esa dirección, se identificaron los principales polígonos industriales donde se agrupa la mayoría de la actividad manufacturera, los cuales se clasificaron en tres tipos: 1) grandes nodos, 2) corredores, y 3) pequeños nodos aislados. ${ }^{5}$ Tras la determinación y el análisis de los polígonos industriales, se agrega una esquematización histórica del proceso de conformación de dichas concentraciones, hasta culminar en la forma de 2003.

Fue necesario partir de ciertos paradigmas morfológicos para orientar la identificación empírica del tipo de estructura espacial de la actividad industrial en la AMCM. En primer lugar se consideró un patrón de corte monocéntrico, caracterizado por tener en la zona central de la ciudad la mayoría de las actividades industriales concentradas en un solo nodo. Asimismo, existe una gran diferencia entre la zona de máxima concentración y la media general, por lo que se supuso que si la intensidad de la actividad de dicha área alcanza dos desviaciones estándar por encima de la media, la distribución se considera monocéntrica.

Los patrones descentralizados, en segundo lugar, describen cuándo la industria manufacturera se encuentra mayoritariamente fuera del centro urbano. Con este criterio se enfrentó el problema de delimitar claramente al centro urbano mismo, ya que tradicionalmente se caracteriza por tener un gradiente decreciente de su concentración económica según se extiende hacia la periferia. Estos esquemas podrán ser concentrados cuando la actividad manufacturera se encuentra predominantemente localizada en subcentros urbanos, o dispersos, cuando la mayoría de las fábricas se distribuyen en toda la ciudad. El patrón disperso no excluye la posible existencia de sutiles subcentros de concentración industrial con una densidad y una participación muy

${ }^{4}$ Esto ocurre porque el VACB se presenta en miles de pesos, por lo que aquellas AGEB con producción menor a 500 pesos no manifiestan ninguna producción.

${ }^{5}$ Las peculiaridades de cada uno de estos tres tipos de concentraciones industriales según su magnitud de la producción se definirán más detalladamente cuando se analicen. 
bajas respecto a la producción metropolitana. A partir de los anteriores paradigmas generales, en el primer inciso del escrito se presentará una esquematización de los modelos de uso de suelo más connotados.

\section{Evolución de los modelos de estructuración del espacio urbano}

El interrogante inicial es determinar la pertinencia de retomar los modelos policéntricos formulados por diversos autores norteamericanos al analizar la evolución de las ciudades de ese país.

Hoyt (1940), en su esquema de sectores plantea que la industria, como las otras actividades, se concentra de forma radial partiendo del centro urbano. Harris y Ullman (1945) afirman que las actividades se agrupan por núcleos; con su propuesta son los primeros en diferenciar entre la industria ligera y la pesada ${ }^{6}$ Garreau (1991) también encontró una tendencia hacia la creación de subcentros urbanos, donde la actividad económica tendía a localizarse en dichas áreas, llegando a superar en importancia a la zona central.

Los anteriores esfuerzos por generalizar la distribución industrial en las ciudades según la experiencia de Estados Unidos han sido extendidos por autores de ese país para adecuarlos a la estructura urbana de las ciudades latinoamericanas, aceptando su especificidad. Griffin y Ford (1980) construyeron un modelo monocéntrico donde la descentralización se limitaba a un corredor comercial que salía de la zona central hacia la periferia. La actividad industrial permanecía en el centro (Griffin y Ford, 1980: 402) (gráfica 1). Quince años después Ford (1996) incorporó en un nuevo esquema algunas características policéntricas en torno a un corredor industrial emplazado a lo largo de una vía de comunicación, férrea o autopista, conectando a la zona central con los suburbios. Este corredor industrial culmina con un parque industrial suburbano donde se alojan las fábricas que demandan grandes extensiones de suelo para almacenamiento (gráfica 2).

Según los anteriores esquemas, parecería que a mediados del siglo Xx todavía persistía una estructura urbana monocéntrica en las ciudades latinoamericanas y que el policentrismo habría aparecido posteriormente. Sin embargo, conforme al modelo de Borsdorf (2003) que incorpora la evolución secular de las ciudades, es posible constatar

\footnotetext{
${ }^{6}$ Burgess (2008 [1925]: 73) ya reconocía la diferente tendencia de emplazamiento entre la industria ligera y la pesada, pero no incorporó a la última en su propuesta espacial de patrón monocéntrico.
} 


\section{GRÁFICA 1}

Modelo espacial de la estructura urbana de las ciudades latinoamericanas elaborado por Griffin y Ford

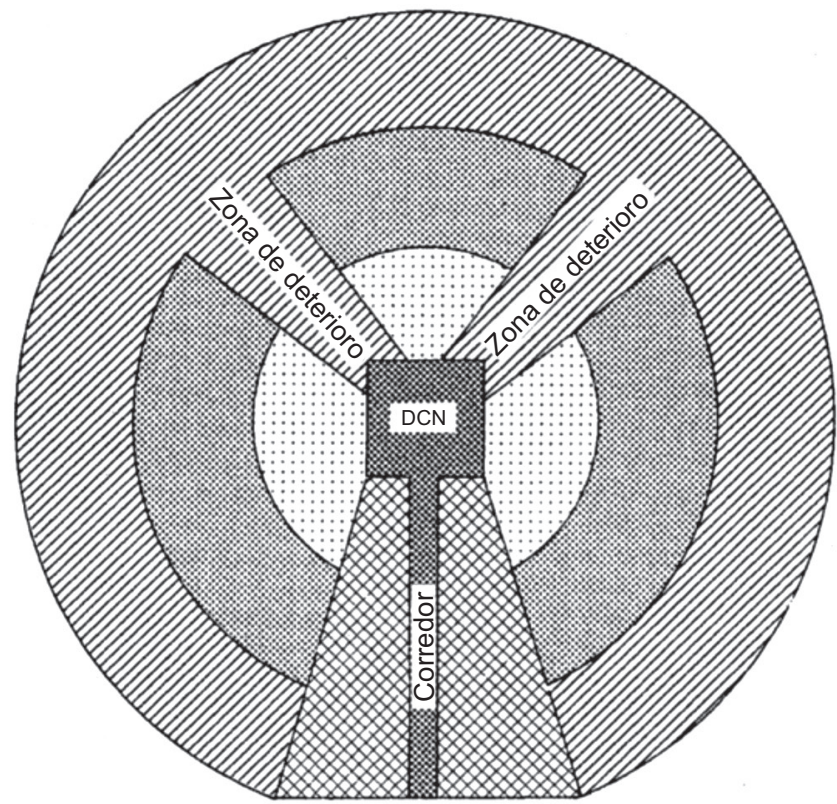

Zona comercial e industrial

Zona residencial de altos ingresos

Zona de consolidación

Zona de crecimiento in situ

Zona de asentamientos ilegales

DCN Distrito central de negocios

FUENTE: Griffin y Ford, 1980. 


\section{GRÁFICA 2}

Modelo espacial de la estructura urbana de las ciudades latinoamericanas elaborado por Ford

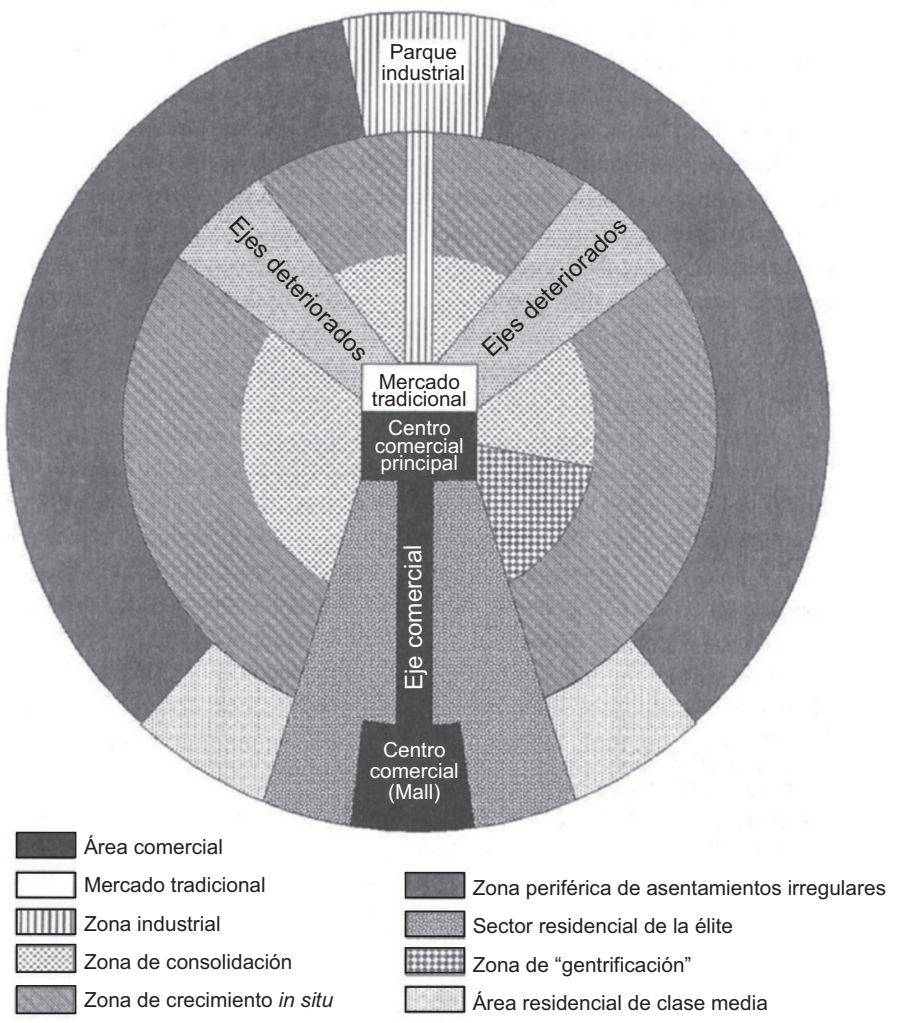

FUENTE: Ford, 1996.

que este proceso de descentralización parece haberse iniciado mucho antes. El autor define cuatro etapas del desarrollo de los asentamientos urbanos latinoamericanos: la época colonial o compacta (de 1550 hasta 1820); la ciudad sectorial (1820 a 1920); la ciudad polarizada (1920 a 1970); y la ciudad fragmentada (1970 a 2000). A partir de la segunda fase, el autor reconoce la formación de corredores industriales que parten de la zona central, en forma similar a la propuesta de Hoyt para las ciudades americanas. Durante la tercera fase identifica 
la formación de zonas industriales en la periferia urbana, sugiriendo el policentrismo a partir de núcleos y corredores (gráfica 3).

Gormsen (1981: 294), por su parte, en un modelo de ciudad latinoamericana de los cincuenta hasta su emergencia metropolitana, describe la creación de nuevas zonas periféricas que se caracterizan por la concentración de establecimientos industriales. Sin embargo también reconoce la formación de áreas de uso mixto con industria dispersa, especialmente en colonias antiguas en proceso de deterioro (gráfica 4). Este autor es de los primeros en incorporar en su modelo espacial la dispersión de la actividad industrial, fenómeno que posteriormente Lang (2003) denominaría edgeless cities, en contraposición con las edge cities de Garreau (1991).

En función de las propuestas anteriores, parecería que las grandes ciudades latinoamericanas están actualmente experimentando una notable descentralización de las actividades económicas, con la industria distribuyéndose policéntricamente a partir de corredores y núcleos. Este fenómeno de dispersión como patrón predominante de la manufactura ha sido investigado por Crowley (1995: 23), quien sostiene que en las ciudades latinoamericanas la actividad industrial se encuentra desperdigada desde tiempo atrás: la gran mayoría de los pequeños establecimientos y algunas plantas de razonable tamaño se distribuyen en toda la zona urbana; sin embargo reconoce la aglomeración industrial históricamente conformada que aún perdura en la distribución actual (gráfica 5). Ford (1996: 439) también acepta que en las zonas habitacionales se pueden encontrar diversos establecimientos industriales. Posteriormente, Crowley (1998: 129) hace referencia a este fenómeno de dispersión de las actividades económicas e incorpora otro concepto peculiar dentro de él: el crecimiento discontinuo característico de la periurbanización.

Borsdorf (2003) hace una descripción más detallada de este proceso de dispersión de la actividad económica mediante el concepto de "ciudad fragmentada", como última etapa del desarrollo urbano. Los parques industriales se tornan ubicuos en toda la zona urbana al no depender significativamente de las vías de comunicación interurbanas que dominaban su criterio de emplazamiento. Esto permitió el surgimiento de nuevos parques industriales en zonas en el interior de las ciudades. El espacio industrial ya no está solamente caracterizado por las grandes zonas industriales, sino también se presenta una morfología mucho más heterogénea. Hidalgo y Borsdorf (2005: 22) definen que los patrones espaciales viven un proceso de fragmentación de estructu- 


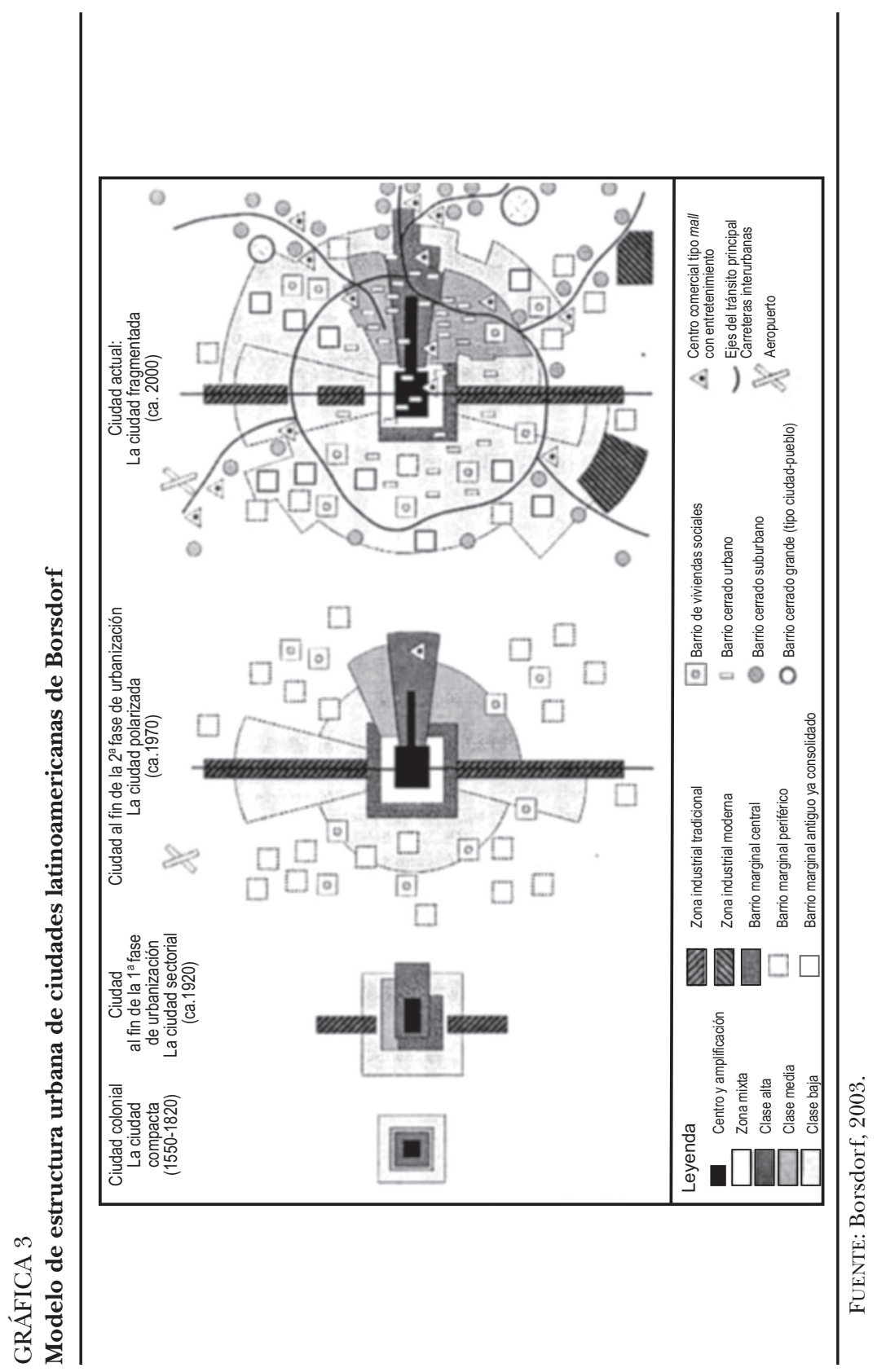




\section{GRÁFICA 4}

Modelo de estructura urbana de ciudades latinoamericanas elaborado por Gormsen

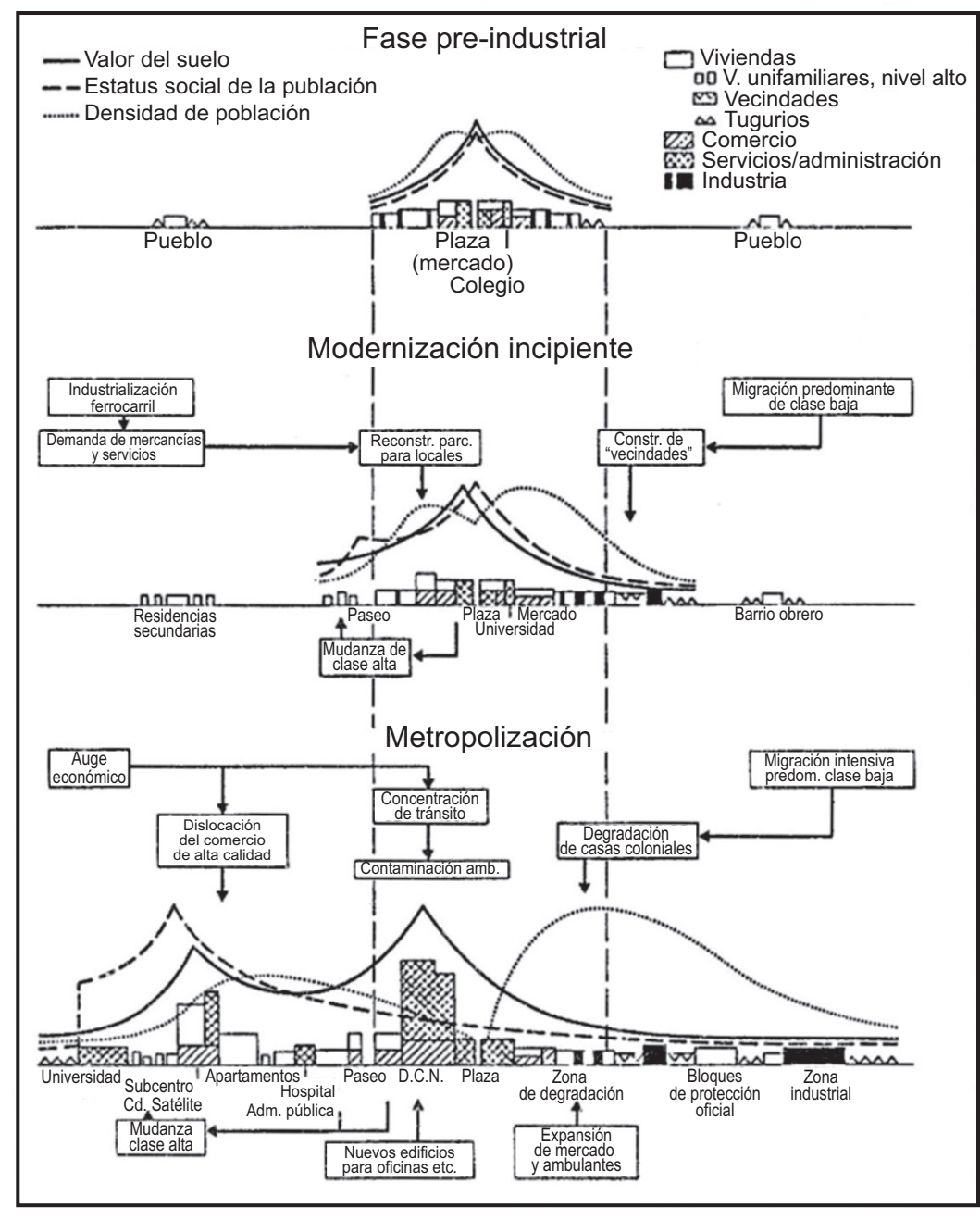

FUENTE: Gormsen, 1981. 


\section{GRÁFICA 5}

Modelo espacial de distribución industrial en las ciudades latinoamericanas elaborado por Crowley

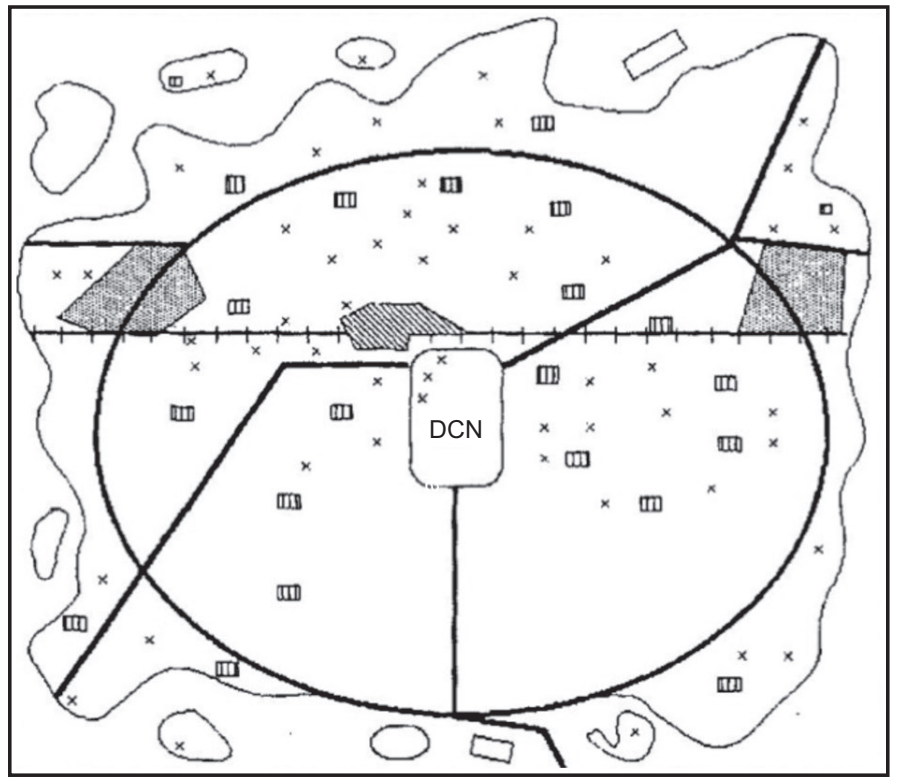
\$ Industria antigua
Industria nueva
inili Fábricas aisladas

$\times$ Pequeñas plantas

— Arterias viales

FUENTE: Crowley, 1995.

ra y funciones, acercándose más a pequeñas áreas de actividad económica, o a lo que los autores denominan patchworks (parches), en contraposición con los modelos homogéneos más claramente ordenados.

Veltz (1999: 55) argumenta que este proceso de fragmentación espacial evidencia la necesidad de describir el territorio urbano a partir de diferencias microespaciales. Las desigualdades que se expresan a una escala más pequeña son ahora las predominantes y contrastantes. La geografía económica es más homogénea a gran escala, pero muy 
heterogénea a pequeña escala. De esta suerte, para la Ciudad de México Ramírez (2006: 64) afirma que en las metrópolis globales sólo algunas áreas pueden ser consideradas realmente entornos globales, manifestándose como enclaves en metrópolis fragmentadas.

Los esquemas anteriores presentan conclusiones diferentes sobre el patrón de organización de las actividades industriales en las ciudades, además de que se refieren a diferentes épocas. Los más recientes destacan la existencia de procesos policéntricos o de dispersión manufacturera, los cuales parecen regir para las ciudades latinoamericanas que experimentan un proceso de descentralización de dicha actividad económica, lo cual se contrastará en el caso de la Ciudad de México que se analizará a continuación.

\section{Superconcentración industrial metropolitana}

El AMCM comprende un total de 4418 AGEB, de las cuales 3867 registraron alguna actividad manufacturera en 2003. El número de establecimientos industriales en la ciudad fue de 46 201, que emplearon 757630 trabajadores y produjeron poco más de 154 mil millones de pesos corrientes. De dicha producción metropolitana, 55 AGEB registraron una producción alta, equivalente a dos desviaciones estándar más que la media de la producción de todas las AGEB, donde se concentraron $71 \%$ del PIB, $29 \%$ de los trabajadores dedicados al sector y apenas $3 \%$ del total de los establecimientos industriales. Esto manifiesta una importante centralización general de la producción industrial ${ }^{7}$ en solamente unas cuantas empresas, ya que $97 \%$ de las unidades económicas restantes produjo tan sólo $29 \%$ del total metropolitano. Durante las décadas de los sesenta y setenta se observó que las grandes y medianas empresas aumentaban su participación en la producción nacional (Garza 1985: 218). A pesar de que en este artículo no se hace un análisis diacrónico que pudiese confirmar esta tendencia, es posible afirmar que se mantiene un alto nivel de centralización general de la producción industrial, cuyas peculiaridades intrametropolitanas se analizarán a continuación.

7 El concepto de centralización general de la producción se refiere al fenómeno de que pocas empresas concentran gran cantidad de la producción (Garza, 1985: 215-228). 


\section{Policoncentraciones industriales en la Ciudad de México}

Adicionalmente a la centralización general de la producción, las 55 AGEB que acumularon $71 \%$ de la producción manufacturera también representan un área muy reducida de la ciudad, esto es, 3\% de la superficie total. Esta alta concentración espacial se confirma al obtener un índice de Gini de 0.89 , esto es, muy cercano a la unidad. ${ }^{8}$ Por medio del análisis microespacial es posible observar que existen diversos puntos de muy alta actividad que evidencian que la organización espacial de la industria se ajusta a un patrón policéntrico con un pequeño conjunto del $3 \%$ de las AGEB con alta producción industrial, las cuales se ubican principalmente al norte de la metrópoli (mapa 1).

El policentrismo observado en la configuración industrial en la Ciudad de México es común en todas las grandes urbes del mundo, por lo que interesa determinar si en la capital mexicana tiene peculiaridades propias vinculadas con su geomorfología y desarrollo histórico. Para ello se procedió a elaborar un análisis más detallado en aquellas AGEB que registraron una producción manufacturera alta.

La visualización espacial de la distribución de la actividad industrial mostró que algunas AGEB con producción muy alta estaban rodeadas por áreas con producción por encima de la media metropolitana, por lo que fue posible determinar polígonos industriales que agruparon más de una AGEB y que registraron concentraciones por encima de la media en torno a núcleos de alta producción.

El proceso analítico consistió en clasificar la intensidad de la concentración del PIB industrial en cuatro categorías. La primera fue la de intensidad baja, que contiene a todas las AGEB con producción inferior al promedio metropolitano. El conjunto de intensidad media agrupa a las áreas con producción entre la media y una desviación estándar por arriba de ella. El tercer intervalo de intensidad alta abarca aquellas

8 Para determinar el grado de concentración de las actividades se utilizó el índice de Gini que cuantifica el nivel de desigualdad de la distribución de las actividades (YuHsin, 2005). El índice tiene un intervalo entre 0 y 1, donde 0 significa una dispersión total y generalizada, mientras que el valor de 1 significa una concentración absoluta en un espacio (describiría un modelo monocéntrico de la actividad económica). La ecuación con la que se calcula el coeficiente es la siguiente:

$$
\text { Gini }=0.5 \sum_{i=1}^{N}\left|X_{i}-Y_{i}\right|
$$

donde $X_{i}=\%$ del área del $\mathrm{AGEB}_{\mathrm{i}} ; Y_{i}=\%$ del PIB industrial del AGEB; $N=$ número total de AGEB. 


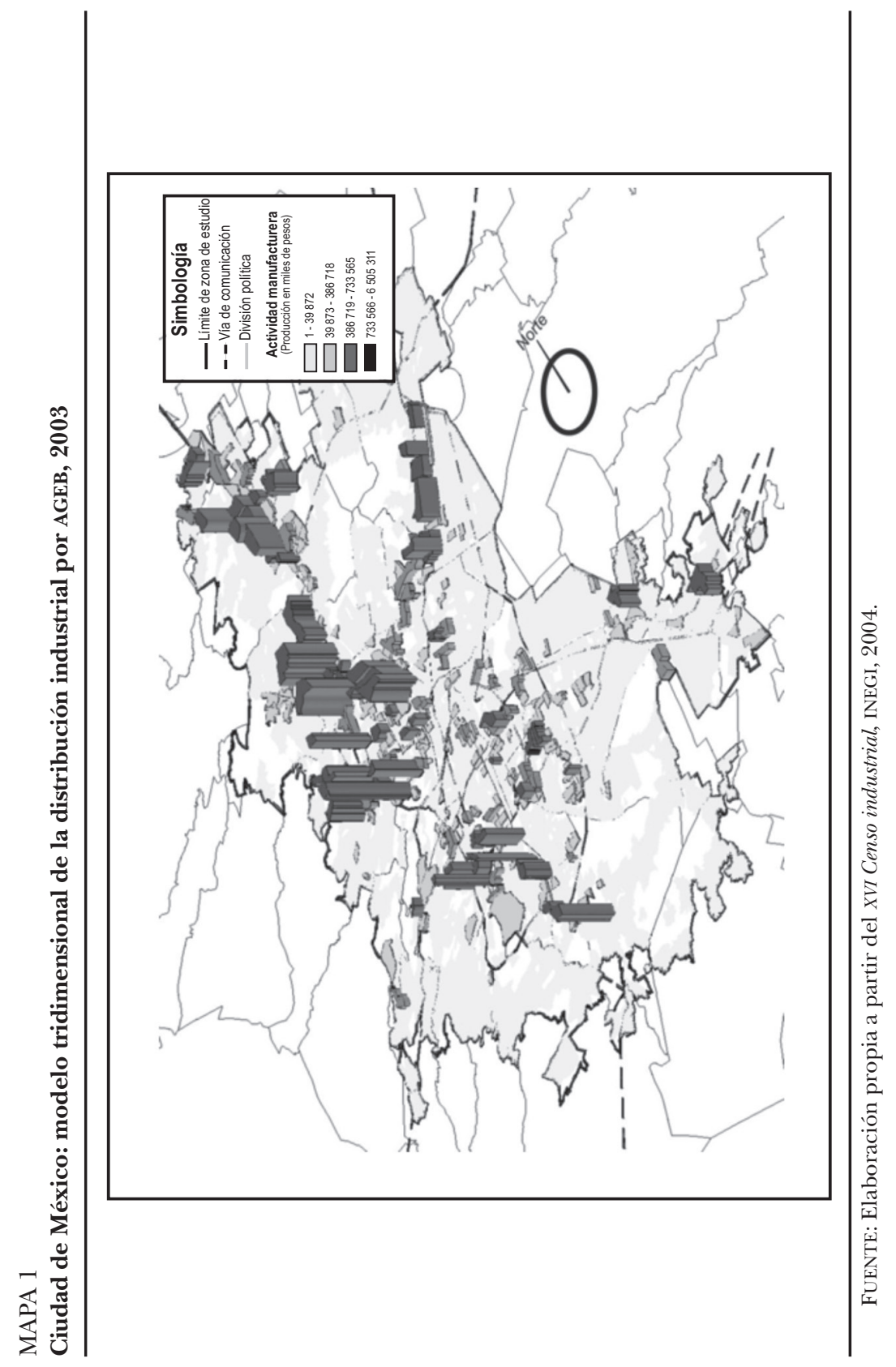


AGEB con PIB industrial entre una y dos desviaciones estándar por encima de la media. Y por último, las AGEB con producción de intensidad muy alta son todas aquellas donde se registra una producción superior a dos desviaciones estándar de dicho promedio.

Con base en el anterior procedimiento se detectaron 55 AGEB con intensidad manufacturera muy alta. Se observó que varias de ellas manifestaban una clara contigüidad espacial, por lo que se les denominó núcleos industriales. Del total de las AGEB con intensidad muy alta, 31 se constituyen en siete núcleos y las 24 restantes están dispersas en toda la ciudad.

Estas siete agrupaciones de AGEB con producción muy alta se encuentran rodeadas por actividad industrial de menor intensidad, pero mayor a la media metropolitana. La conjunción de los siete núcleos más las AGEB espacialmente contiguas y con producción superior al promedio constituyen siete grandes polígonos industriales localizados en las circunscripciones de: Azcapotzalco, Naucalpan, Tlalnepantla, Ecatepec, Cuautitlán Izcalli, Iztapalapa y La Paz. ${ }^{9}$ En Ecatepec coexisten dos núcleos cercanos en una sola área de influencia, por lo que se les identificó únicamente como un solo polígono de muy alta actividad (mapa 2).

A las 24 AGEB con actividad industrial muy alta, pero sin contigüidad con otra AGEB de esa categoría fuera de los polígonos previamente mencionados, se les denominó nodos aislados. Algunos de ellos muestran áreas contiguas con actividad mayor a la media, pero de manera muy incipiente. Algo diferente ocurrió en el municipio de La Paz, donde se identificó un núcleo compuesto por una AGEB, pero con una amplia área contigua con intensidad media. Por su tamaño, este conglomerado se clasificó como polígono industrial, según se mencionó anteriormente.

La mayoría de los polígonos industriales (del 1 al 5 en el mapa 2), se encuentran emplazados al norte de la ciudad debido en buena medida a que es la mejor orientación hacia otros importantes mercados nacionales, como pudieran ser las ciudades de Monterrey y Guadalajara, y hacia Estados Unidos, que constituye históricamente el principal mercado del comercio internacional de México. Con relación al polígono de Iztapalapa, se cree que su producción industrial se orienta al mercado interno de la ciudad debido a su proximidad con la Central

9 Estos polígonos se conocen con el nombre de la demarcación donde están mayoritariamente localizados, pues hay casos en los que sobrepasan los límites municipales y delegacionales donde se ubican. 


\section{MAPA 2}

Ciudad de México: siete grandes polígonos industriales

según niveles de distribución de la producción industrial por AGEB, 2003

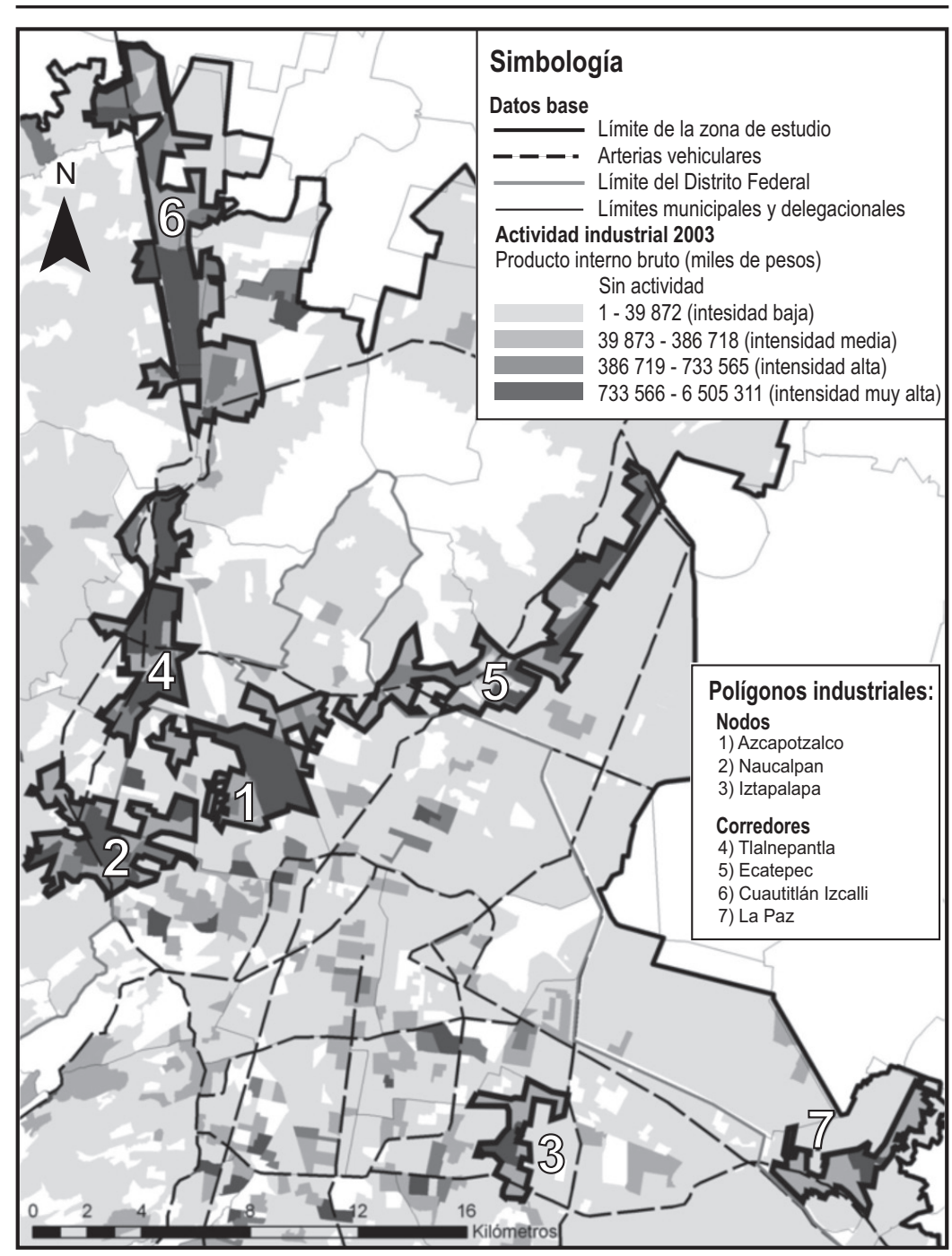

FUENTE: Elaboración propia a partir del XVI Censo industrial, INEGI, 2004. 
de Abasto y a su propensión a especializarse en bienes de consumo inmediato. Por otro lado, la zona industrial de La Paz podría ser el destino de aquellos establecimientos que no tienen acceso a los grandes polígonos del norte de la ciudad, posiblemente por el valor del suelo, además de que pudieran servir al mercado local y al sureste del país, pues se ubica sobre la carretera a Puebla. También permite canalizar la producción a las regiones del norte y a Estados Unidos, ya que utilizando la carretera libre a Texcoco se accede a las vías que comunican a la ciudad hacia el norte.

La concentración industrial microespacial requiere de la aglomeración de un conjunto de condiciones generales de la producción (infraestructura y equipamiento) en zonas muy específicas en el interior de las delegaciones y los municipios conurbados donde se ubican las principales empresas manufactureras. Las redes de comunicaciones que incrementan la accesibilidad a estas zonas, como las vías férreas y las carreteras, tienen un área de influencia muy circunscrita. Esto ocasiona que en el interior de las demarcaciones caracterizadas con muy alta actividad industrial, como la delegación Azcapotzalco y los municipios conurbados de Tlalnepantla, Naucalpan, Ecatepec y Cuautitlán Izcalli, haya una importante concentración industrial e infraestructural en solo un fragmento de su territorio.

La aglomeración en el interior de las demarcaciones anteriores es reforzada por la normatividad de uso de suelo, pues las áreas en que se permite la actividad industrial se derivan de un proceso de regularización de los principales asentamientos fabriles ex post, más que de acciones de planeación, regulación y control de usos de suelo ex ante. Tal normatividad territorial motiva que la manufactura se continúe concentrando en estas zonas permitidas, acentuando las diferencias de actividad industrial dentro de las delegaciones y municipios.

Los nodos aislados están localizados principalmente en las delegaciones Miguel Hidalgo y Azcapotzalco, además de Coyoacán en la zona sur. Cabe destacar que estas AGEB se caracterizan en su mayoría por tener un predominio de suelo habitacional, por lo que las fábricas se encuentran rodeadas de viviendas. Por tal razón se piensa que sus actividades tienen un bajo impacto negativo para los hogares, y son poco susceptibles a las deseconomías de conectividad que se generan en dichas zonas por la congestión vial que presentan.

Los siete polígonos industriales concentran $53.6 \%$ del PIB manufacturero de la urbe, lo cual implica una magnitud de producción 57 veces mayor que la media metropolitana. Estas zonas agruparon 31 AGEB 
con muy alta actividad, que en su mayoría formaron los núcleos industriales, más otras 100 que tenían una producción superior a la media metropolitana, con lo cual totalizaron 131 (cuadro 1). En cuanto a la centralización general de la producción, en estas zonas se encuentra solamente $6.3 \%$ de los establecimientos manufactureros, los cuales se caracterizan por ser de gran tamaño según el personal ocupado, con 92.1 trabajadores por unidad económica, es decir, 5.6 veces más que el promedio de la ciudad de 16.4 (cuadro 1). Adicionalmente, estas empresas también centralizan la producción pues su PIB/UE es de 28.3 millones de pesos, lo que equivale a 8.5 veces más que la media metropolitana.

Existe sin embargo, cierto grado de dispersión de la producción manufacturera que se realiza en los nodos aislados. Éstos están conformados por AGEB de muy alta producción manufacturera, e incluso varios de ellos superan el PIB de los núcleos de los polígonos. Su dispersión contrarresta en cierta medida el grado de concentración espacial de la actividad industrial a escala metropolitana. En conjunto contienen $32.9 \%$ de la producción metropolitana y abarcan apenas una superficie menor a $1 \%$ de la ciudad. En los nodos aislados se tiende a centralizar la producción algo más que en los polígonos, pues promedian 145.3 trabajadores. De forma similar se tiene la producción por planta, pues producen 113.6 millones de pesos por unidad económica, un monto 34 veces superior a la media (cuadro 1 ).

Esto evidencia un fenómeno interesante, pues la centralización general de la producción no necesariamente está vinculada con la concentración espacial. Tanto en los polígonos industriales -cuya cualidad principal es la aglomeración de la producción- como en los nodos aislados -cuyo comportamiento es completamente opuesto-es posible identificar el fenómeno de la centralización general de la producción, que incluso es mayor en los casos dispersos.

Los siete grandes polígonos industriales, a su vez, se clasificaron en dos grupos en función de su morfología espacial. Por un lado están las concentraciones compactas con una geometría que se aproxima más a una circunferencia, y en este trabajo se les definió como nodos industriales. McDonald, Giuliano y Small explican que los nodos son las zonas que concentran la actividad económica y articulan la estructura urbana (en Garrocho y Campos, 2009: 828). Estos nodos pueden tener efectos significativos en el funcionamiento de la ciudad, especialmente en lo que se refiere al sistema de transporte y distribución de la población (McMillen, 2003: 2). Dentro de esta 


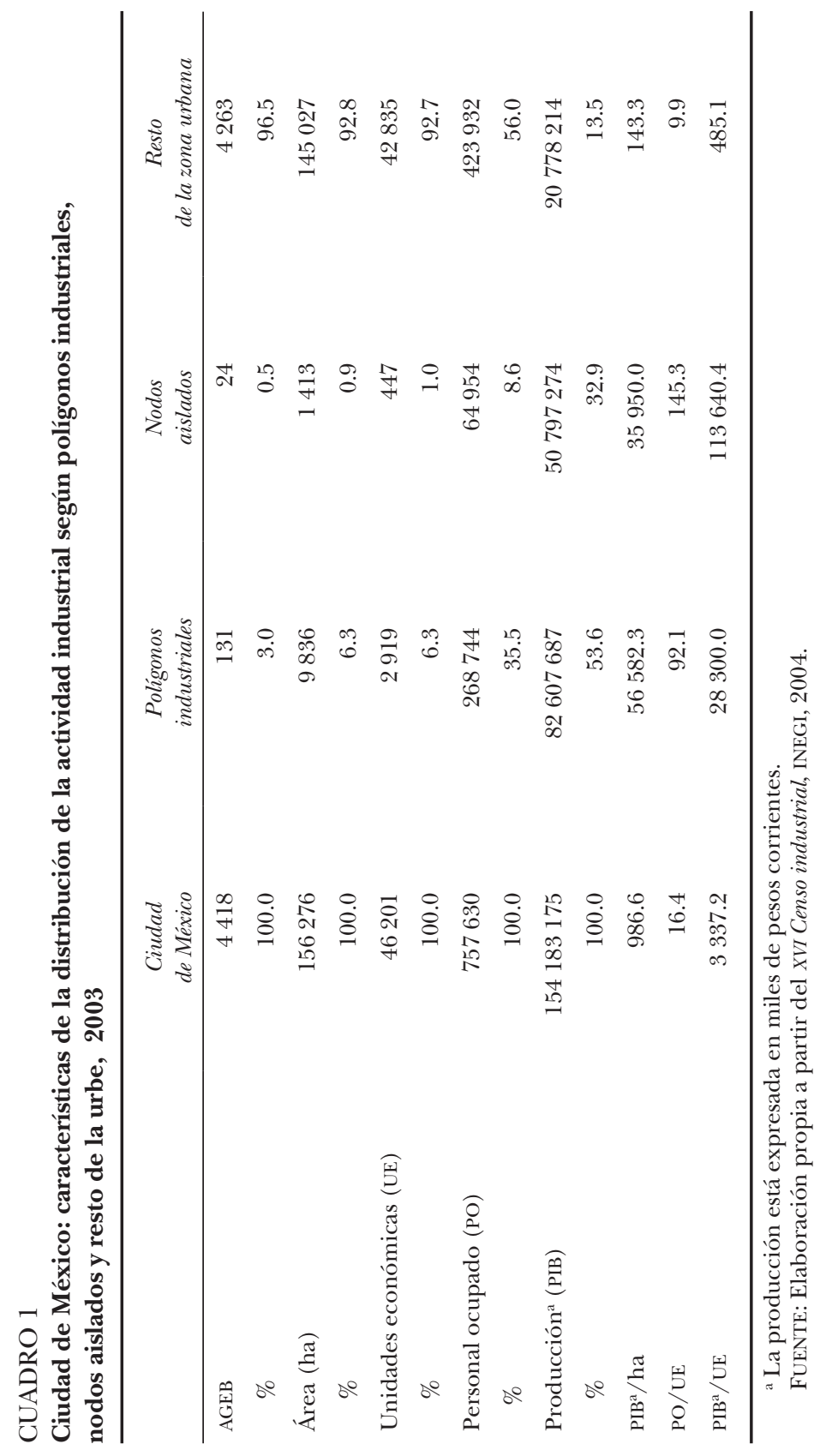


categoría se ubicaron los polígonos de Azcapotzalco, Naucalpan e Iztapalapa (mapa 2).

Por otro lado, se identificaron los polígonos cuya figura es alargada y extendida, denominándolos corredores industriales. Estas concentraciones tienen efectos similares a los de los nodos anteriores, pero con diferente morfología, ya que se conforman a lo largo de importantes vías de comunicación. Dentro de esta categoría se encuentran los polígonos de Cuautitlán Izcalli, Tlalnepantla, Ecatepec y La Paz (mapa 2).

Esta diferenciación permitió profundizar en las cualidades del patrón espacial policéntrico existente en la Ciudad de México, según el análisis de sus polígonos de concentración industrial. En concreto, es necesario evaluar si el patrón de descentralización concentrada de la manufactura en el interior de la urbe tiene las cualidades que diversos autores mencionan como características de un modelo policéntrico, así como determinar cuáles son sus particularidades específicas.

\section{Megacorredor industrial históricamente construido}

La distribución de la manufactura en el AMCM permite apreciar nítidamente un conjunto de concentraciones que corresponden a un patrón industrial de tipo multinuclear. No obstante, por la constitución de corredores industriales, especialmente el de Tlalnepantla-Cuautitlán Izcalli y el de Ecatepec, es posible identificar con mayor precisión el patrón organizacional de la actividad industrial como concentrado en siete polígonos industriales clasificados en tres nodos y cuatro corredores (mapa 2).

En la bibliografía sobre el tema existen múltiples evidencias de que la actividad industrial intrametropolitana tiende a seguir patrones de descentralización concentrada en subcentros fuera del núcleo principal. Por ejemplo, en Cincinnati (Barff, 1987), Los Ángeles (Giuliano y Small, 1991), así como en Toronto, Montreal y Vancouver (Shearmur y Coffey, 2002), hay aglomeraciones fabriles similares a los nodos industriales que se identifican en la urbe mexicana. Como resultado de estudios semejantes a los anteriores, se han creado modelos urbanos que pretenden determinar los patrones espaciales de la distribución industrial. Diversas propuestas (Harris y Ullman, 1945; Gormsen, 1981; Crowly, 1998) señalan que la distribución industrial tiende a concentrarse en subcentros localizados en la periferia urbana. En la Ciudad 
de México, no obstante, se aprecia la formación de cuatro corredores industriales que absorben una mayor producción que la de los tres nodos, además que desde una perspectiva general no existe un núcleo central (mapa 1). En la capital mexicana el modelo tradicional policéntrico tendría la peculiaridad de estar conformado por cuatro grandes corredores y tres nodos que giran en torno a un distrito central caracterizado por una elevada concentración de las actividades de comercio y servicios, pero con casi nula producción industrial. ${ }^{10}$

Específicamente, el polígono principal fue el corredor Cuautitlán Izcalli, que se extiende por 27 kilómetros de largo y representó $12.8 \%$ del PIB industrial metropolitano. En segundo lugar se encuentra el nodo de Naucalpan con $11.5 \%$ del PIB, además de que es el que más establecimientos y personal ocupado absorbe (cuadro 2).

En concordancia con el patrón identificado en el AMCM, existen estudios que detectan concentraciones industriales que forman corredores a lo largo de las vías de comunicación, como en Phoenix, Arizona, donde se evidencia la estrecha relación entre la actividad manufacturera y el trayecto de las vías ferroviarias (Ó hUallacháin y Leslie, 2009). En esa urbe, los establecimientos industriales están dotados de "espolones" que les permiten trasladar vagones a dicha vía de transporte desde su interior. Una ciudad latinoamericana que muestra una tendencia hacia la formación de corredores fue Bogotá, donde tres cuartas partes del empleo industrial se ubican en uno sólo (Kyu Sik, 1981: 240).

Con el fin de plasmar esta realidad, se han formulado modelos que reconocen la existencia de formaciones extendidas debido a la influencia determinante de las vías de comunicación. Hoyt (1940) ya había definido la importancia de la infraestructura vial para la conformación de la estructura urbana, en especial para la localización de las fábricas. Diversas concentraciones de la actividad se logran a partir de la existencia de vías con origen en el centro de la ciudad; como resultado, dichos sectores se iniciaban en la frontera del distrito central de negocios para extenderse hacia la periferia urbana. Es interesante el postulado de Hoyt, pues de manera incipiente hace referencia al factor temporal para definir la estructura espacial de la ciudad. La evidencia empírica del AMCM muestra que el punto de partida de estos corredores no es el distrito central de negocios tradicional, sino los nodos de

${ }^{10}$ Se ha demostrado que la Ciudad de México muestra en el largo plazo, de 1960 a 2008, una persistente concentración de las actividades comerciales y de servicios en la ciudad central (Garza, 2012). 


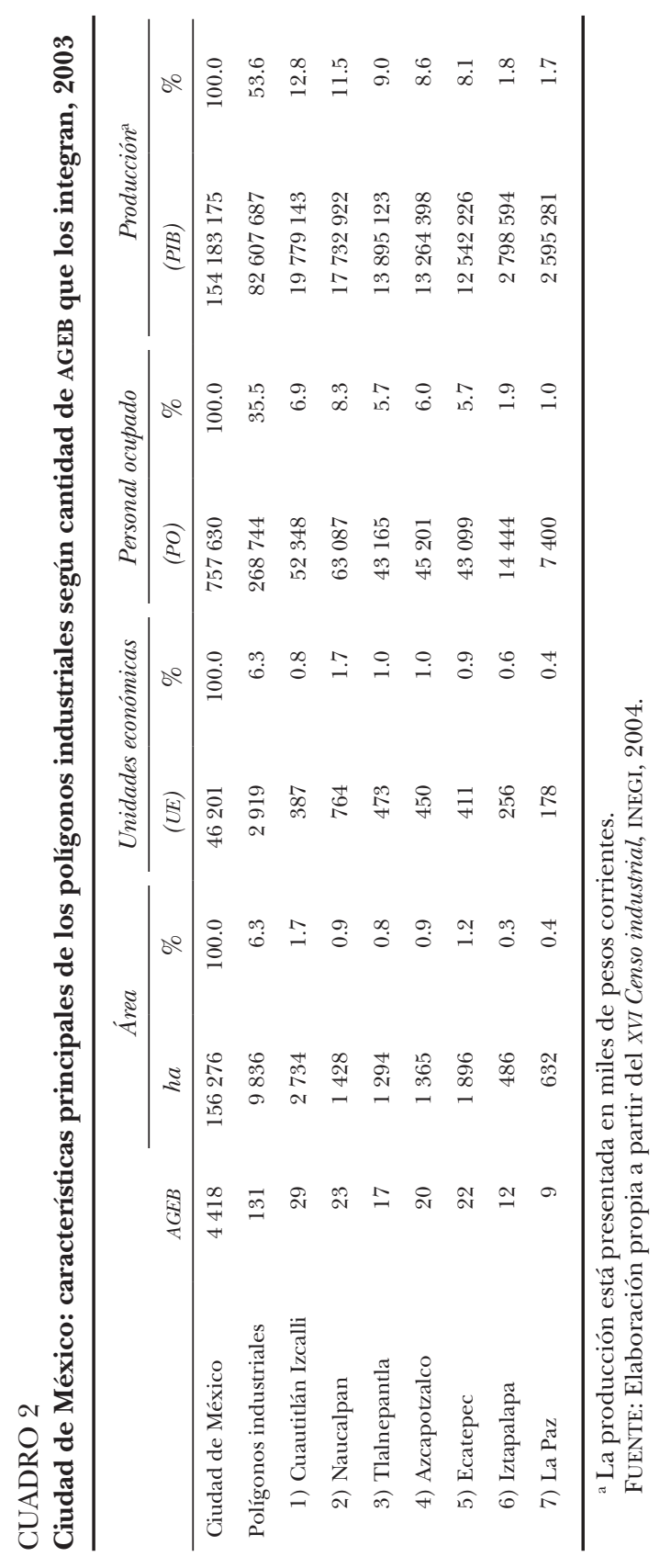


Azcapotzalco y Naucalpan, que constituyen los polígonos industriales más antiguos de la urbe.

Algunos de los modelos de ciudades latinoamericanas incorporan la formación de nodos y corredores donde se concentra la actividad industrial. Ford (1996), en un esquema estático, menciona algo similar al postulado de Hoyt: que los corredores industriales se inician a partir del centro comercial principal. Sin embargo, el corredor terminaba en una zona industrial consolidada, fenómeno que no se manifiesta en la Ciudad de México, dado que los núcleos se emplazan en el interior de los corredores. Su estructura espacial se puede explicar como un proceso histórico de fundación-consolidación, de lo cual deriva que los núcleos se ubiquen en el centro del polígono, mientras en sus contornos se encuentren zonas de menor magnitud. Como se verá más adelante, los corredores industriales evolucionan siguiendo ciertas etapas de desarrollo que difícilmente permiten la existencia de un área industrial con mayor actividad y más consolidada en su límite extremo.

Borsdorf (2003) elaboró un modelo donde incorporó el desarrollo histórico para comprender la estructura de las actividades urbanas. En su propuesta identifica la creación de corredores industriales y clasifica a las plantas localizadas en su interior como tradicionales. Adicionalmente incorpora concentraciones periurbanas y suburbanas como nodos, donde se establece la industria moderna. En la Ciudad de México se observa una distribución completamente opuesta, pues los nodos industriales están más bien ubicados en la zona central y, debido al momento histórico de su creación hacia mediados del siglo pasado, alojan unidades económicas que producen mercancías tradicionales, principalmente en el ramo de fabricación de prendas de vestir, en contraste con las fábricas de más reciente creación en las periferias de los corredores.

En el AMCM sobresalen los siete grandes polígonos identificados y que han sido clasificados en cuatro corredores y tres nodos industriales, los cuales surgen en forma conjunta con el acelerado crecimiento de su mancha urbana, estimulado por el dinámico desarrollo industrial experimentado. Aunque se abordará más a detalle en la siguiente sección, cabe mencionar que la génesis de los nodos industriales fue a partir de la construcción de parques industriales desde mediados del siglo XX, cuando la concentración de las condiciones generales infraestructurales permitió el acrecentamiento de las economías externas. Los corredores han sido el resultado del desarrollo de las vías ferroviarias y carreteras que, teniendo como origen un nodo industrial, facili- 
tan el emplazamiento de fábricas a lo largo de ellas hasta conformar un corredor manufacturero propiamente dicho.

La estructura interna de los polígonos industriales de la Ciudad de México también evidencia diferencias respecto a los modelos analizados. Una peculiaridad de dichas propuestas es que existe un núcleo de máxima concentración circundado por otros secundarios que deben seguir un esquema centro-periferia de gradientes decrecientes.

En efecto, Clark (2000: 145) afirma que la disminución paulatina de la actividad económica del centro a la periferia ocurre como respuesta a las variaciones del valor de suelo y de la accesibilidad que presentan las diferentes áreas. Agrega que aunque ello es característico del modelo monocéntrico, también es posible observarlo en el patrón policéntrico.

En el AMCM, sin embargo, los núcleos del corredor La Paz y de los nodos de Azcapotzalco e Iztapalapa concentran un elevado porcentaje de la producción de todo el polígono, que alcanza los valores de 59, 77 y $61 \%$, respectivamente (cuadro 3). Como corolario, las AGEB circundantes que forman el área de influencia presentan una drástica reducción en la intensidad de la actividad industrial, mientras en los tres polígonos anteriores no aparecen núcleos secundarios, por lo que se pasa del central al resto del polígono (cuadro 3). Por ende, las AGEB de producción intermedia no responden a un comportamiento de gradiente donde, según la teoría, la producción debería disminuir progresivamente conforme se aleja de los núcleos de máxima actividad. Una posible causa de la gran diferencia de producción entre los núcleos y el resto del área que conforman los polígonos, es que el origen de los primeros es en su mayoría la oferta inmobiliaria en parques industriales públicos o privados. El conjunto de servicios complementarios y las condiciones generales de la producción (CGP) construidas en el interior de estos proyectos industriales benefician a los establecimientos instalados en su interior, manifestándose una alta concentración de la producción. ${ }^{11}$ Fuera de estos parques las CGP se difuminan, por lo que el valor del suelo y la accesibilidad, elementos calificados como clave por Clark para explicar el gradiente, se reducen drásticamente, por lo que no se presenta dicha peculiaridad dentro de los polígonos industriales de la Ciudad de México (mapa 3).

Por otro lado, el nodo de Naucalpan y los corredores de Cuautitlán Izcalli, Tlalnepantla y Ecatepec, además de los núcleos principales

${ }^{11}$ Para un análisis detallado de la categoría histórica de las CGP véase Garza, 2013. 
MAPA 3

Ciudad de México: estructura espacial de los nodos y corredores del norte según intensidad de la producción industrial, 2003

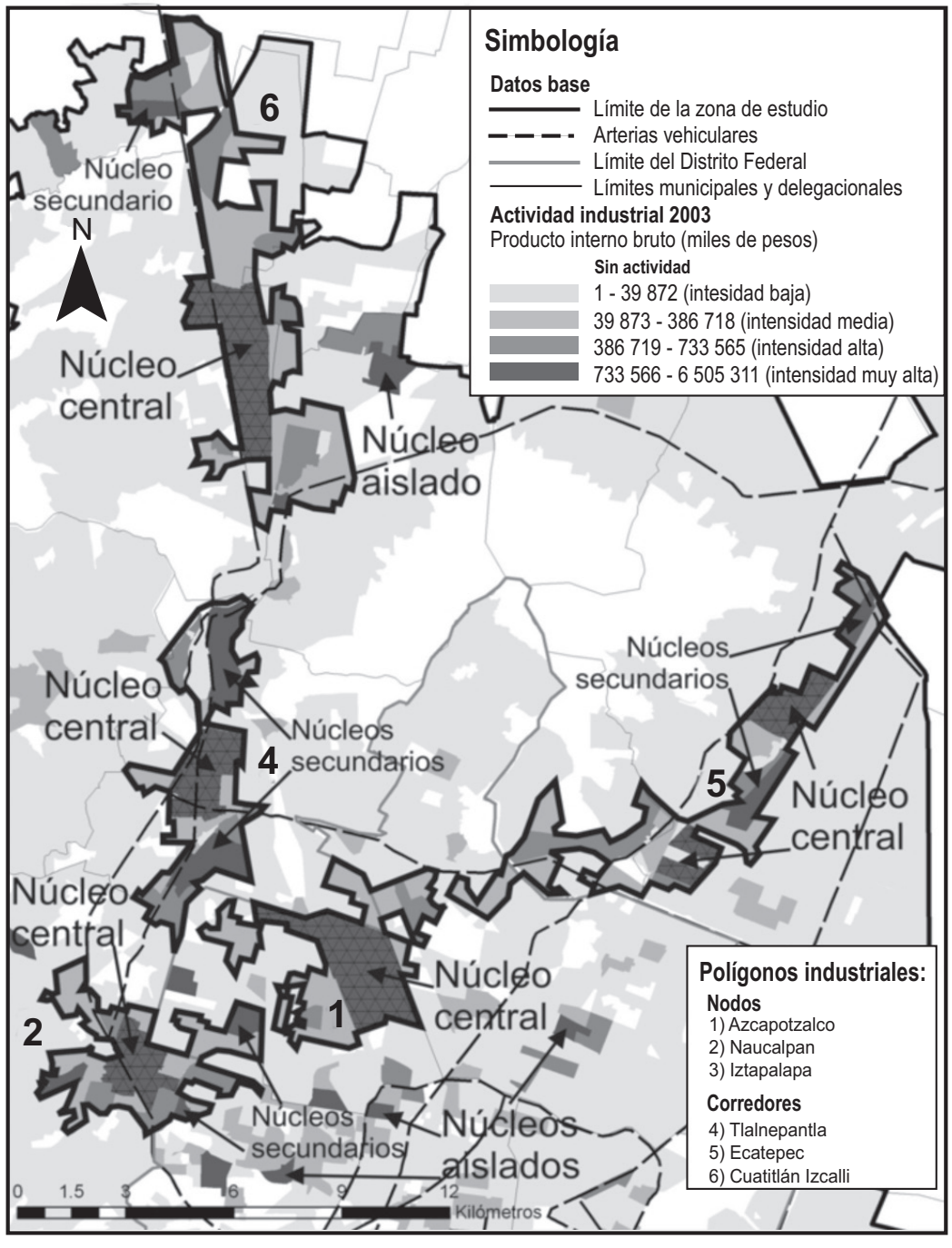

FUENTE: Elaboración propia a partir del XVI Censo industrial, INEGI, 2004. 
formados por más de una AGEB con alta actividad industrial, contenían algunas áreas aisladas de este tipo, pero inmersas en los nodos y corredores (mapa 3). A estas áreas de alta producción, pero sin contigüidad con otra AGEB de alta intensidad, se les denomina núcleos secundarios; por lo que la estructura interna de estos polígonos industriales se podría caracterizar como multinuclear, estando éstos inmersos a su vez en una organización industrial metropolitana de corte policéntrico.

De los cuatro polígonos con núcleos secundarios, solamente en Cuautitlán Izcalli y Naucalpan se observó una elevada concentración del PIB industrial en los núcleos principales, al contener 56 y $50 \%$, respectivamente (cuadro 3). En los dos restantes corredores de Tlalnepantla y Ecatepec, la estructura polinuclear es más notable dado que los núcleos no alcanzan a concentrar la mayoría de la actividad manufacturera. En el corredor de Ecatepec, específicamente, sus dos núcleos principales sólo aglomeran $45 \%$ de la producción del polígono. En ambos corredores, la mayoría de la actividad se encuentra distribuida en todos los núcleos, tanto principales como secundarios. Este fenómeno es interesante, pues es posible detectar el policentrismo tanto a escala metropolitana, a partir de la formación de nodos y corredores industriales, como en el interior de algunas de dichas concentraciones (cuadro 3).

Aunque se podría decir que la Ciudad de México evidencia una distribución industrial descentralizada en forma concentrada, sería más preciso caracterizarla por la existencia de un patrón espacial de multicorredores. En la capital mexicana no fue el distrito central el nodo manufacturero principal, tal como lo define Hoyt. En la segunda mitad del siglo XX se conformaron los nodos industriales de Azcapotzalco y Naucalpan, vinculados con pequeños núcleos aislados distribuidos en la delegación Miguel Hidalgo. A partir de ellos se fueron conformando paulatinamente los corredores de Ecatepec y Tlalnepantla, para continuar la aglomeración industrial hasta consolidar el corredor de Cuautitlán Izcalli, que actualmente es el más importante de todos (cuadro 2 y mapa 3 ).

Específicamente, el modelo tridimensional de la distribución manufacturera presentado en el mapa 1 muestra una alta actividad en la zona norponiente del AMCM que se inicia en los nodos de Naucalpan y Azcapotzalco, para continuar en los corredores de Tlalnepantla y Cuautitlán Izcalli (mapas 1 y 2). Estos cuatro polígonos concentraron $42 \%$ de la producción industrial de la urbe en 2003. Considerando que su cristalización es el resultado de al menos un siglo de evolución, 


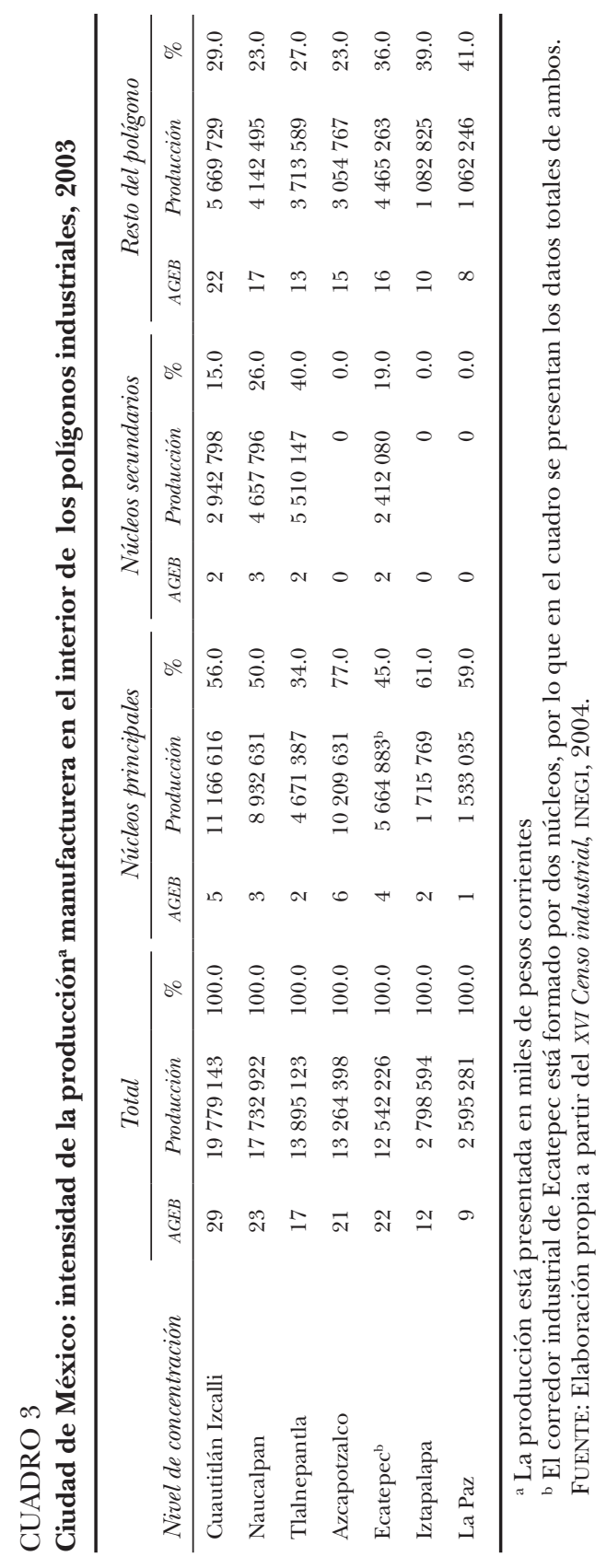


se podría pronosticar heurísticamente como escenario futuro la consolidación de un megacorredor industrial bicéfalo que se inicia en los nodos de Naucalpan y Azcapotzalco, a partir de los cuales su parte toral se continúa por los corredores de Tlalnepantla y Cuautitlán Izcalli (mapas 1 y 2). Paralelamente, se esperaría una creciente articulación entre el nodo de Azcapotzalco y el corredor de Ecatepec, que imprimiría al megacorredor la forma de una gran ye $(Y)$. Su morfología se deriva de la existencia de la Sierra de Guadalupe, que los separa de manera infranqueable, constituyendo un claro ejemplo de la influencia de las variables morfogenéticas en la estructuración intrametropolitana de las actividades económicas y la población.

\section{Polígonos industriales y evolución urbanística}

El proceso secular de formación de una metrópoli es resultado de la yuxtaposición de espacios existentes en constante renovación y nuevas áreas construidas que pueden o no haberse planificado. La ciudad es el producto final de esa sucesión histórica de espacios construidos que se reinterpretan según culminan las diferentes etapas de su desarrollo. Ya sea como centro de control administrativo, militar, empresarial o como medio de producción e intercambio, la ciudad debe cubrir los requerimientos económicos y sociales de las clases dominantes. Es imperativo, por ende, tener una referencia histórica del desarrollo urbanístico de la ciudad para comprender la distribución contemporánea de las actividades económicas y de la población en su territorio y, en especial para los propósitos de este artículo, el patrón que siguen las manufacturas.

La Ciudad de México experimentó un acelerado proceso de industrialización durante la segunda mitad del siglo Xx gracias a la implementación de la política económica estatal proteccionista o de crecimiento hacia adentro, etapa que se conoce como el "milagro económico". ${ }^{12}$ Conforme al carácter histórico de la configuración espacial de las actividades productivas referido, en este inciso se analiza el patrón de distribución industrial de 2003 siguiendo las diferentes etapas del crecimiento territorial de la Ciudad de México. Se intenta imprimirle una dimensión diacrónica, aunque meramente ilustrativa, al estudio sincrónico del patrón industrial de 2003 presentado en el acápite anterior.

12 Para un mayor conocimiento de las características de la etapa de industrialización acelerada de la Ciudad de México, entre 1950 y 1970, véase Garza, 1985. 
La periodización analítica utilizada corresponde a las décadas de la segunda mitad del siglo Xx, dado que los siete polígonos industriales identificados fueron creados durante ese medio siglo. Se trata de elaborar algunas inferencias históricas, por preliminares que sean, del comportamiento de la localización fabril en los nodos y corredores industriales en la urbe.

\section{Evolución de los nodos industriales}

En 1960 la extensión de la trama urbana del AMCM era de 296 km² y en el norte ya existían los nodos industriales de Azcapotzalco y Naucalpan. Estos dos polígonos de alta actividad manufacturera se ubicaban en la periferia urbana de ese entonces. Adicionalmente a estas dos concentraciones, existía otra formada en torno a la Refinería 18 de Marzo, que actualmente prácticamente desapareció como consecuencia del cierre de la planta en 1991 y de la extensión del tejido urbano en toda la zona.

El polígono de Azcapotzalco se inició con las primeras fábricas que se establecieron en la zona en los años treinta. En 1944, sin embargo, se consolidó institucionalmente por un decreto presidencial que fundó una zona industrial en la colonia Vallejo, acelerando el proceso de concentración de plantas manufactureras. Durante la década de los cincuenta fue el área fabril más extensa de la Ciudad de México gracias a la llegada de nuevas firmas, atraídas por la construcción de las estaciones de ferrocarriles de carga de Pantaco y Ceylán, así como del Rastro de Ferrería, que sirvieron como infraestructura importante para la producción manufacturera.

Actualmente, el núcleo del nodo de Azcapotzalco se caracteriza por concentrar un conjunto de condiciones generales de producción que evitan el proceso de desindustrialización de dicha zona, ya completamente absorbida por el área urbana con las subsecuentes deseconomías de urbanización que esto conlleva. Es decir, normalmente la saturación de las vías de comunicación, del suelo y la incompatibilidad de uso con otras actividades urbanas, fungen como fuerzas centrífugas que motivan la emigración de las antiguas plantas industriales a la nueva periferia urbana. Sin embargo, a pesar de que en 2003 la zona estaba totalmente inmersa en la ciudad, conserva su naturaleza de alta concentración manufacturera con $8.6 \%$ del PIB industrial de la urbe en 2003 (cuadro 2). La estación ferroviaria de Pantaco, ubicada al 
suroeste del nodo industrial, sigue en operaciones y permite la introducción de líneas de ferrocarril en el interior de la zona industrial Vallejo. Ello facilita a las empresas el acceso a este servicio de transporte sin la necesidad de trasladar sus productos o recibir su materia prima en la estación principal. Adicionalmente, debido a la importancia del intercambio de bienes entre las fábricas de la Ciudad de México con las de Estados Unidos, se creó la aduana de Pantaco. La proximidad de este servicio al productor reforzó la aglomeración de la actividad manufacturera en esta zona, facilitando los procesos de exportación de bienes y la importación de maquinaria e insumos para la producción.

Un tercer elemento que contuvo la desindustrialización del nodo de Azcapotzalco a medida que se incorporaba completamente dentro del tejido urbano fue la instalación del Instituto Politécnico Nacional en sus inmediaciones en la vecina delegación Gustavo A. Madero, cuya función es capacitar la mano de obra que demanda la actividad manufacturera. El cuarto factor que reforzó la importancia del nodo industrial fue la construcción de la línea 6 del Metro. Esta red de transporte facilitó el acceso de los trabajadores mediante la ubicación de dos estaciones dentro del área del parque industrial Vallejo.

No obstante, la zona industrial está viviendo un proceso de servicialización, ya que diversos establecimientos industriales están siendo sustituidos por empresas de servicios y comercio. El ejemplo más claro es la reconversión de la antigua planta de ensamblado de vehículos de la General Motors ubicada en la zona de Santa Bárbara, que ahora se está transformando en un centro de servicios informáticos conocido como Tecnoparque, destinado a empresas con altos flujos de información.

El nodo industrial de Naucalpan, similar al anterior, se formó principalmente en la década de los cincuenta, cuando el área era aún periferia urbana. Este nodo también experimentó su completa incorporación al tejido urbano más denso, lo que ha implicado un proceso paulatino de sustitución de actividades industriales por comerciales y de servicios (Dirección General de Desarrollo Urbano, 2007: 20). El polígono manufacturero se localiza a un lado de la villa de Naucalpan de Juárez, fundada durante el periodo colonial como sitio minero.

La localización de la actividad económica suele ocurrir en zonas periféricas a las ciudades en las cuales se puede acceder a servicios urbanos como agua potable, energía eléctrica y comunicaciones, pero que tienen menores precios del suelo (Ramírez, 2006: 65). La actividad 
manufacturera, especialmente en Naucalpan, y como se verá más adelante también en Tlalnepantla y Ecatepec, tiende a emplazarse en la periferia de los poblados suburbanos cercanos a alguna vía de transportación regional importante, con el fin de aprovechar la infraestructura urbana local y la existente en la Ciudad de México.

Actualmente, pese a los graves problemas de saturación vial, la actividad industrial en Naucalpan se mantiene gracias a la conectividad que brinda el boulevard Ávila Camacho, construido durante la segunda mitad del siglo xx. Esencialmente, el nodo industrial de Naucalpan está formado por seis fraccionamientos industriales, de los cuales Industrial Naucalpan, Industrial Alce Blanco, Industrial La Perla e Industrial Atoto, forman parte del núcleo principal. Adicionalmente, Industrial Tlatlico y el parque industrial Naucalpan se emplazan al oeste de los anteriores; este último forma un núcleo secundario en la zona poniente del nodo industrial. ${ }^{13}$

En el AMCM, además de los dos grandes polígonos industriales de Azcapotzalco y Naucalpan, existen nodos aislados en la zona sur, y se estima que la mayoría de las empresas se establecieron cuando el área ya estaba urbanizada. La industria química es la predominante en esta parte de la urbe. Desde un inicio se reportaba que estos establecimientos estaban mezclados con las zonas habitacionales, evidencia que puede comprobarse al constatar que estas AGEB aisladas con alta producción industrial ya estaban inmersas en la Ciudad de México en 1960 .

En síntesis, en 1960 sólo existían dentro de la trama urbana de la metrópoli los nodos industriales de Azcapotzalco, en el Distrito Federal, y Naucalpan, en ese municipio conurbado del Estado de México (mapas 2 y 4). En el inciso siguiente se verá cómo se fueron integrando al tejido urbano los corredores industriales partiendo de un grupo pequeño de plantas manufactureras localizadas originalmente en la periferia de la urbe.

\section{Formación de los corredores industriales}

En función de la extensión territorial del AMCM en 1970, es posible observar que la tendencia de su crecimiento se modificó en relación

13 Las dimensiones y límites de los diferentes fraccionamientos industriales se presentan en el Plan Municipal de Desarrollo Urbano de Naucalpan de Juárez, 20062009. 
con la década pasada. Mientras que en 1960 la zona sur fue el principal destino para la construcción de nuevas edificaciones, en 1970 tenía un mayor crecimiento en las zonas norte y oriente (mapa 4). Esta última creció por la fundación de Ciudad Netzahualcóyotl, mediante la creación del municipio con el mismo nombre en 1963. La expansión al norte de la ciudad fue promovida por la construcción de una serie de zonas industriales y la consolidación de Ciudad Satélite, submetrópoli periférica iniciada en los años cincuenta en Naucalpan. ${ }^{14}$

Las concentraciones manufactureras que destacan en este periodo son los actuales corredores industriales de Tlalnepantla y de Ecatepec, que durante la década de los sesenta estaban situados en la periferia urbana. Aunque la llegada de las primeras fábricas ocurrió durante los cincuenta, la zona industrial continuó expandiéndose a lo largo de las vías de comunicación debido a la disponibilidad de suelo. Estos dos casos muestran que los corredores requirieron de décadas de evolución para tener la morfología actual.

Como se puede desprender de una atenta comparación de los mapas 2 y 4, los primeros asentamientos industriales de Tlalnepantla estaban contiguos a zonas suburbanas de la Ciudad de México en los años sesenta. ${ }^{15}$ Sucedió en este corredor un fenómeno similar a la evolución urbanística del nodo de Naucalpan. Las zonas industriales de Puente de Vigas y Los Reyes, en el extremo sur del municipio, se encuentran adjuntas a Ciudad Satélite, la cual durante la década siguiente se extendió al sur de Tlalnepantla fundando las colonias El Mirador y Vista Hermosa, ubicadas al poniente de las zonas industriales mencionadas. Por otro lado, el núcleo principal ubicado en la zona central del municipio también se conformó bajo el mismo patrón. En este caso, los fraccionamientos Industrial Tlalnepantla, Industrial San Lorenzo y San Nicolás Tlaxcolpan se localizan al oriente del antiguo centro de Tlalnepantla. Aunque las vías ferroviarias provenían de la Ciudad de México, el servicio de transportación atendía igualmente a estas nuevas zonas industriales.

14 En la actualidad se conoce genéricamente como Satélite y se ha extendido a colonias en los municipios de Atizapán de Zaragoza y Tlalnepantla, tales como Lomas Verdes, Echegaray, La Florida y Fuentes de Satélite <http://es.wikipedia.org/wiki/ Ciudad_Satelite/Mexico>.

15 Originalmente se diseñó un mapa que incluía la expansión de la mancha urbana de 1960 a 1990 (mapa 4), al mismo tiempo que los cuatro estratos de intensidad de la producción industrial representados en diferentes colores (mapa 2). Su realización en blanco y negro hacía prácticamente imposible su lectura, por lo que se procedió a presentarlos por separado dejando al lector la molestia de estar contrastando ambos mapas (véase el mapa conjunto en colores en Cruz, 2012: 240). 
MAPA 4

Ciudad de México: etapas del crecimiento urbano, 1960-1990

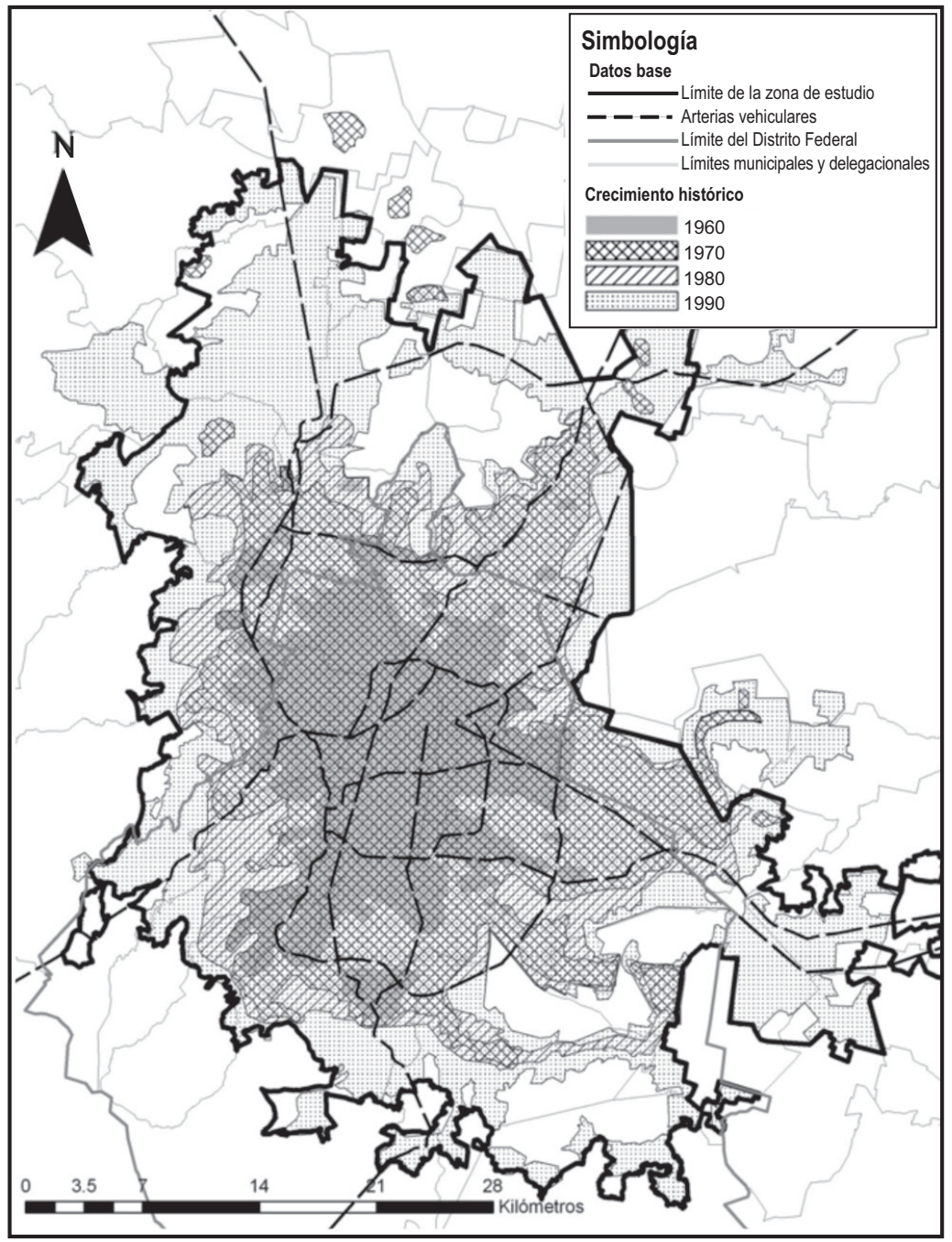

FUENTE: Elaboración propia a partir del XVI Censo industrial, INEGI, 2004. 
La actividad industrial en Ecatepec, por su parte, empezó desde la década de los cuarenta, cuando se establecieron en su territorio algunas grandes empresas manufactureras. A finales de los sesenta era posible reconocer la formación del corredor con la aparición de diversas zonas industriales ubicadas en los linderos de la línea ferroviaria hacia Veracruz y la carretera a Pachuca. Otro factor que determinó la localización de las fábricas fue la cercanía a los poblados originales de Ecatepec. Cuando las zonas industriales de Xalostoc y Esfuerzos Nacionales se emplazaron en los límites de la Ciudad de México, al sur del municipio existían las colonias San Miguel y San José Xalostoc, desde donde se extendieron las redes de infraestructura para dotar de servicios a la zona industrial. De manera incipiente, también se podía distinguir la zona industrial de Santa Clara, al este del poblado del mismo nombre y al poniente de las vías de comunicación anteriormente mencionadas. Importa destacar que en 1970 el corredor industrial de Ecatepec ya se encontraba enteramente dentro de la trama urbana metropolitana, y que llegó a consolidarse a principios del siglo XXI, como se expuso en el inciso anterior (mapas 2 y 4 ).

En 1980 hubo un claro freno en el crecimiento del AMCM. Así, mientras de 1960 a 1970 registró un incremento de 340 km² en su tejido construido, durante la década siguiente se había extendido apenas $198 \mathrm{~km}^{2}$, totalizando $834 \mathrm{~km}^{2}$ a finales de la década de los setenta. En este periodo, sin embargo, la expansión del área urbana fue más homogénea desde el punto de vista geográfico, es decir, ya no se presentó el fuerte impulso hacia el norte y el oriente que se experimentó en la década anterior. Se observa un proceso de despliegue siguiendo el contorno urbano prevaleciente, pero ligeramente acentuado en el norte y el poniente (mapa 4 ).

Durante esta etapa la zona industrial de La Paz, localizada en el municipio mexiquense de ese nombre, que colinda al oeste con Iztapalapa y al norte con Netzahualcóyotl, aparece en lo que era la periferia oriente de la ciudad. Las primeras unidades manufactureras se asientan al sur del poblado Los Reyes Acaquilpan. Su desarrollo sigue la misma lógica de los corredores industriales de Tlalnepantla y Ecatepec, pues en 1980 sólo estaba formada su zona oeste, la más cercana a la metrópoli. Estos primeros asentamientos manufactureros aprovecharon la cercanía de la cabecera municipal, no conurbada en ese año, para cubrir sus requerimientos de infraestructura y, al mismo tiempo, utilizar la carretera federal México-Puebla. En 1980, sin embargo, aún no estaba inserto en la trama metropolitana lo que sería 
en 2003 el núcleo industrial central del polígono industrial La Paz (mapas 2 y 4 ).

Los corredores del norte seguían su proceso de expansión hacia las nuevas fronteras periurbanas. En Tlalnepantla se desarrollaba la zona industrial de Barrientos y en Ecatepec la de Cerro Gordo, lo cual impulsaba el crecimiento del tejido urbano metropolitano con la consiguiente infraestructura requerida por las nuevas plantas (mapas 2 y 4).

Hacia 1990 se reinicia la expansión urbana en el norte y suroriente de la ciudad. Nuevamente es posible explicar el crecimiento al oriente de la urbe a partir de la creación de grandes áreas habitacionales construidas en los municipios de Ixtapaluca y Valle de Chalco. Por otro lado, el desdoblamiento en la zona norte se puede atribuir a la creación de nuevos parques fabriles.

El corredor industrial Cuautitlán Izcalli es la más reciente formación emplazada en la periferia urbana de los ochenta. No obstante, cabe aclarar que la industria de esta zona inició su incipiente arribo desde la década de los sesenta. El establecimiento de la industria está estrechamente vinculado con la fundación del área habitacional de Cuautitlán Izcalli, creada en 1973 con el propósito de otorgar vivienda a la gran cantidad de población inmigrante en la urbe en los setenta. Desde principios de la década existían dos parques industriales: el Complejo Cuamatla y La Luz. En ellos se localizaban empresas importantes como la Ford, Bacardí y Mundet, pero gracias a la construcción del gran conjunto habitacional a orillas de la Autopista México-Querétaro se presenció un proceso de proliferación de los parques industriales (Asesores de Urbanismo y Ecología S.C., 2008: 61). Como ocurrió en los corredores industriales de Tlalnepantla y Ecatepec, el proceso de conformación de esta zona llevó varias décadas. Durante los inicios del siglo XXI las empresas aún siguen instalándose al norte de este corredor industrial, especialmente en la zona de Tepotzotlán, ahora la nueva zona periurbana (mapas 2 y 4 ).

Adicionalmente, hacia 1990 terminó de formarse el corredor cuya consolidación se realiza en 2003 en el municipio de La Paz. Con el crecimiento del área urbana se fueron estableciendo nuevas industrias a lo largo de la carretera México-Texcoco, dando un giro a lo que parecía sería un corredor industrial a lo largo de la carretera federal México-Puebla. En 1990 el núcleo industrial principal del corredor de La Paz ya estaba totalmente integrado al tejido construido de la urbe, tal como se aprecia al contrastar los mapas 2 y 4. 


\section{Conclusiones: construcción histórica de la organización industrial}

El proceso de reconfiguración de las manufacturas en el Área Metropolitana de la Ciudad de México (AMCM) es la resultante espacial de su acelerado proceso de industrialización que se inició a mediados del siglo xx. Dicho proceso, en primera instancia, constituyó un patrón de descentralización que se concentró en un conjunto de tres nodos y cuatro corredores ubicados principalmente al norte de la urbe. En segunda instancia, se observan nodos aislados que contrarrestan el grado de aglomeración en los siete grandes polígonos industriales identificados.

En los inicios del siglo XXI la organización polinuclear de la industria en el AMCM adquirió la forma de multicorredores. Específicamente, se detectaron cuatro claramente desarrollados, y cada uno de ellos tiene su origen en un nodo semicentral: Tlalnepantla, Ecatepec, Cuautitlán Izcalli y La Paz. Los tres primeros se localizan en la zona norte de la ciudad, constituyéndose en las principales aglomeraciones de establecimientos fabriles con una clara orientación hacia el intercambio de bienes e insumos industriales con el norte del país y con Estados Unidos, al mismo tiempo que abastecen al principal mercado interno nacional, esto es, la Ciudad de México. La formación de los nodos industriales de Azcapotzalco y Naucalpan en la periferia norte de la urbe a mediados del siglo Xx, marcó la pauta para la creación de nuevos establecimientos manufactureros que en las décadas posteriores fueron conformando los actuales corredores de Tlalnepantla, Ecatepec y Cuautitlán Izcalli.

Si se toma en cuenta el anterior patrón de distribución espacial de las manufacturas en el AMCM, es posible pronosticar que continuará la tendencia hacia la consolidación de los corredores que han surgido a lo largo de vías de comunicación y cuyo nacimiento se localiza en un gran subcentro industrial. Esta organización tiene similitud con el modelo de sectores de Hoyt (1940), pero con la diferencia de que no es solamente un sector industrial el que surge fuera de la zona central, sino que son varios los corredores que se inician en un subcentro industrial que previamente se había desconcentrado de dicha zona. Adicionalmente es posible encontrar aglomeraciones secundarias, ya sea en forma de nodos (Iztapalapa) o de corredores (La Paz), en otras partes de la ciudad como resultado de diferentes factores históricos de su evolución. La aparición del nodo de Iztapalapa está vinculada con la concentración del comercio al por mayor en la Cen- 
tral de Abasto. Respecto a La Paz, su emergencia está relacionada con la existencia de la carretera que comunica a la ciudad con mercados importantes, como la ciudad de Puebla, y con puertos de gran relevancia para el comercio exterior, como Veracruz.

El tercer elemento que define el patrón de la distribución industrial en el AMCM son los nodos aislados, los cuales se encuentran dispersos en toda la zona urbana. Estos establecimientos se caracterizan por tener muy alta producción y estar rodeados por zonas habitacionales. Este fenómeno confirma el planteamiento de Borsdorf sobre la existencia de industrias que no están sujetas a las vías de comunicación interurbanas. Dicho autor menciona que durante la etapa de ciudad fragmentada, cualidad de las metrópolis de inicios del siglo XXI, es posible encontrar nuevos parques en su interior, lo que no sucede en la Ciudad de México pues la industria dispersa data desde finales de las décadas de los sesenta y ochenta, por lo que no se encuentran en nuevas aglomeraciones fabriles.

A partir de los hallazgos realizados es posible pronosticar heurísticamente que la conformación industrial en el AMCM se orienta a expandir de los grandes polígonos industriales del norte de la urbe hacia las nuevas zonas periurbanas. A partir de su dinámica de crecimiento se puede prever la emergencia de un megacorredor industrial bicéfalo que principia en los nodos de Naucalpan y Azcapotzalco, y se extiende hacia los corredores de Tlalnepantla y Cuautitlán Izcalli en uno de sus extremos, y en el otro hacia el de Ecatepec. Se continuará consolidando esta gigantesca "Y", cuyo extremo superior está separado por la Sierra de Guadalupe. Como corolario, se advierte que los pequeños nodos y corredores tenderán a sufrir una pérdida relativa de su participación en la producción industrial. No se vislumbra su desaparición en el futuro previsible, pero sufrirán el deterioro paulatino de la infraestructura y las deseconomías externas que la saturación metropolitana conlleva, teniendo como resultado que sea difícil mantener a sus empresas. Es decir, la competitividad de las grandes zonas industriales irá en aumento, en detrimento de las pequeñas concentraciones. Éstas, sin embargo, podrán transformarse en centros comerciales y de servicios.

El análisis diacrónico de los polígonos industriales identificados, que sólo fue posible esquematizar, evidencia que el proceso de descentralización sigue de manera más o menos paralela las etapas de la evolución del AMCM. Es difícil concebir que la gran industria buscase emplazarse en la zona central, donde la acelerada dinámica urbanísti- 
ca produce indefectiblemente una elevada saturación vial y de suelo, lo cual hace imposible su establecimiento.

Lo que ha mostrado la esquematización histórica es que se vive un proceso constante de transformación de la estructuración de la industria en el AMCM. Aunque los nuevos establecimientos buscan las ventajas locacionales de la periferia urbana, como resultado de la constante expansión de la urbe invariablemente terminan por ser absorbidos por su tejido urbano. La dificultad o imposibilidad de trasladar la gran cantidad de capital fijo a un nuevo emplazamiento hace altamente costoso el cambio de ubicación de las plantas, de ahí que permanezcan en las zonas industriales que dejan de ser periféricas. Esta situación crea la ilusión de que la planta fabril se estableció dentro de la zona urbana consolidada, cuando en realidad un estudio temporal evidenciaría que originalmente se trataba de una zona periurbana. En forma paralela se van asentando nuevas fábricas que, al igual que en el pasado, buscan las ventajas de la periferia de la ciudad, aparentando un proceso de descentralización "nuevo", esto es, diferente de la existencia de plantas industriales dentro del tejido urbano de la ciudad.

En conclusión, para entender científicamente el fenómeno de la configuración industrial es necesario realizar un análisis que aplique una metodología de corte histórico-estructural. ${ }^{16}$ Otro elemento significativo es la importancia de los poblados suburbanos para determinar la formación de los parques o fraccionamientos industriales. Las ventajas que brindan dichos asentamientos son la dotación de servicios básicos de infraestructura que las fábricas requieren inicialmente para funcionar, así como la disponibilidad de mano de obra. Si bien es cierto que las grandes obras carreteras o ferroviarias son un factor de vital importancia para la concentración industrial, especialmente para aquellos sectores que atienden a mercados ubicados fuera de las urbes, el emplazamiento de los pequeños poblados en la periferia urbana es un factor de atracción de las nuevas zonas industriales.

A reserva de realizar un análisis más detallado en el futuro, se esperaría que las nuevas firmas manufactureras de tecnología avanzada y de una alta inversión de capital que decidan instalarse en el AMCM eviten la periferia urbana y prefieran las zonas vacantes de los actuales polígonos. Los precios del suelo son aún asequibles y no representan

${ }^{16}$ En la tesis de la cual este artículo forma parte, se realizó un estudio más riguroso de la evolución histórico-estructural de la industria en la Ciudad de México, partiendo de la organización de los obrajes en la ciudad colonial y la emergencia de la industria fabril en el siglo XIX (Cruz, 2012: cap. III). 
una participación significativa en el monto de la inversión total. No obstante, la instalación de las plantas medianas y pequeñas, o de las que requieran grandes extensiones de tierra, podrá seguir orientándose hacia la periferia y localizarse en antiguas poblaciones cercanas a la Ciudad de México. Como en el pasado, ello les permitirá aprovechar los beneficios de la infraestructura más limitada existente, pero a un precio menor del suelo en comparación con el de los polígonos industriales consolidados.

La mayoría de los modelos que esquematizan el tipo de estructura urbana de las ciudades las supone como si aparecieran instantáneamente y no como producto de la historia y resultado final de siglos de evolución. Otros, como los de Gormsen (1981) y Borsdorf (2003), le imprimen un carácter histórico en forma de estáticas comparativas que, aunque más realistas, sufren del mismo problema que los modelos acrónicos, el de ignorar las variables morfogenéticas que determinan en buena medida la estructura que adquieren las ciudades, principalmente de tipos climático, hidrológico, geomorfológico, así como edafológico, y de la vegetación de los ecosistemas urbanos. Adicionalmente, no cuantifican las proporciones del uso del suelo que deberían ocupar las diferentes actividades económicas, las viviendas y el equipamiento urbano, lo cual constituye, quizás, el aspecto más viable para universalizar las características de la organización del espacio urbano.

Formulada en términos generales, la conclusión cardinal del estudio es que la microconfiguración de la industria en el AMCM se ajusta, en primer lugar, al patrón policéntrico establecido por los modelos de estructura urbana. No obstante, presenta la peculiaridad de seguir un proceso de descentralización concentrada que tiende a conformar un megacorredor industrial que constituye una gigantesca " $\mathrm{Y}$ ", la cual parte de los nodos de Naucalpan y Azcapotzalco para seguir, como su extensión principal, hacia los corredores de Tlalnepantla y Cuautitlán Izcalli y, como prolongación secundaria, hacia el de Ecatepec. En segundo lugar tiene una porción significativa de la industria dispersa por todo el territorio metropolitano, lo cual se ajusta a las etapas de evolución urbanística que ha seguido la ciudad en los últimos dos siglos, así como a las variables morfogenéticas que la caracterizan. Estas peculiaridades hacen imposible ajustar el patrón multicorredor-dispersión industrial encontrado en la Ciudad de México a los modelos estándar estudiados, pero sí coincide completamente con el determinismo que le imprime la construcción histórica de las condiciones generales de la producción. 
Cruz y Garza, CONFIGURACIÓN MICROESPACIAL DE LA INDUSTRIA

\section{Bibliografía}

Aguilar, Guillermo y Concepción Alvarado (2004), "La reestructuración del espacio urbano de la Ciudad de México. ¿Hacia una metrópoli multimodal?", en Guillermo Aguilar (coord.), Procesos metropolitanos y grandes ciudades, México, Universidad Nacional Autónoma de México / Miguel Ángel Porrúa, pp. 264-307.

Asesores de Urbanismo y Ecología S.C. (2008), Plan Municipal de Desarrollo Urbano: Ciudad Cuautitlán Izcalli, Toluca, Gobierno del Estado de México.

Barff, Richard (1987), "Industrial Clustering and the Organization of Production: A Point Patern Analysis of Manufacturing in Cincinnati, Ohio", Annals of the Association of American Geographers, vol. 77, núm. 1, pp. 89-103.

Berry, Brian (1971), "Internal Structure of the City", en Larry Bourne (coord.), Internal Structure of the City, Toronto, Oxford University Press, pp. 97-103.

Borsdorf, Axel (2003), "Cómo modelar el desarrollo y la dinámica de la ciudad latinoamericana", Eure, vol. 29, núm. 86, pp. 37-49.

Burgess, Ernest (2008) [1925], "The Growth of the City: An Introduction to a Research Project”, en John Marzluff, Eric Shulenberger, Wilfriedy Endlicher y Marina Alberti (coords.), Urban Ecology: An International Perspective on the Interaction between Humans and Nature, Nueva York, Springer, pp. 71-78.

Caravaca, Inmaculada y Ricardo Méndez (2003), "Trayectorias industriales metropolitanas: nuevos procesos, nuevos contrastes”, Eure, vol. 29, núm. 86, pp. 37-50.

Clark, William (2000), "Monocentric to Polycentric: New Urban Forms and Old Paradigms", en Gary Bridge y Sophie Watson (coords.), A Companion to the City, Oxford, Blackwell Publishers, pp. 139-154.

Crowley, William (1995), "Order and Disorder: A Model of Latin American Urban Land Use", Yearbook of the Association of Pacific Coast Geographers, vol. 57, pp. 9-31.

Crowley, William (1998), "Modeling the Latin American City", Geographical Review, vol. 88, núm 1, pp.127-130.

Cruz Muñoz, Fermín Alí (2012), "Configuración espacial de la industria en la Ciudad de México”, tesis de doctorado en Estudios Urbanos y Ambientales, México, Centro de Estudios Demográficos, Urbanos y Ambientales, El Colegio de México.

Dirección General de Desarrollo Urbano (2007), Plan Municipal de Desarrollo Urbano de Naucalpan de Juárez, Naucalpan, Ayuntamiento Constitucional de Naucalpan de Juárez.

Duranton, Gilles y Henry Overman (2006), Exploring the Detailed Location Patters of UK Manufacturing Industries Using Microgeographic Data, Londres, Centre for Economic Policy Research.

Escolano, Severino y Jorge Ortiz (2005), "La formación de un modelo policéntrico de la actividad comercial en el Gran Santiago (Chile)”, Revista de Geografía Norte Grande, núm. 34, pp. 53-64. 
Ford, Larry (1996), "A New and Improved Model of Latin American City Structure", The Geographical Review, vol. 86, núm. 3, pp. 437-440.

Garreau, Joel (1991), Edge City: Life on the New Frontier, Nueva York, Doubleday. Garrocho, Carlos y Juan Campos (2009), "Estructura espacial del empleo terciario en el Área Metropolitana de Toluca, 1993-2003”, en Gustavo Garza y Jaime Sobrino (coords.), Evolución del sector servicios en ciudades y regiones de México, México, El Colegio de México, pp. 827-875.

Garza, Gustavo (1985), El proceso de industrialización en la Ciudad de México, 1821-1970, México, El Colegio de México.

Garza, Gustavo (2012), "Distribución espacial del sector servicios en la Ciudad de México, 1960-2008”, Estudios Demográficos y Urbanos, vol. 27, núm. 1 (79), pp. 9-55. Disponible en <http://cedua.colmex.mx>.

Garza, Gustavo (2013), Teoría de las condiciones y los servicios generales de la producción, México, El Colegio de México.

Garza, Gustavo y Jaime Sobrino (2000), "Distribución intrametropolitana de la industria, el comercio y los servicios", en Gustavo Garza (coord.), Ciudad de México en el fin del segundo milenio, México, El Colegio de México, pp. 185-194.

Giuliano, Genevieve y Kenneth Small (1991), "Subcenters in the Los Angeles Region”, Regional Science and Urban Economics, núm. 21, pp 163-182.

Gormsen, Erdmann (1981), "Die Städte im spanischen Amerika. Ein Zeiträumlichen Entwicklungsmodell der letzten hundert Jahre", Erdkunde, vol. 35, núm 4, pp. 290-303.

Griffin, Ernst y Larry Ford (1980), "A Model of Latin American City Structure”, Geographical Review, vol. 70, núm. 4, pp. 397-422.

Harris, Chauncy y Edward Ullman (1945), "The Nature of Cities", Annals of the American Academy of Political and Social Science, vol. 242, núm. 7, pp. 7-17.

Hidalgo, Rodrigo y Axel Borsdorf (2005), "La exclusión residencial y el desarrollo de la ciudad moderna en América Latina: de la polarización a la fragmentación. El caso de Santiago de Chile”, Geographicalia, núm. 48, pp. 5-29.

Hoyt, Homer (1940), "Urban Decentralization", The Journal of Land and Public Utility Economics, vol. 16, núm. 3, pp. 270-276.

INEGI (1999), Metodología, Censos económicos 1999, Aguascalientes, Instituto Nacional de Estadística, Geografía e Informática.

INEGI (2004), Metodología para las actividades del sector industrias manufactureras, Aguascalientes, Instituto Nacional de Estadística y Geografía.

Kyu Sik, Lee (1981), "Intraurban Location of Manufacturing Employment in Colombia”, Journal of Urban Economics, vol. 9, núm. 2, pp. 222-241.

Lang, Robert (2003), Edgeless Cities: Exploring the Elusive Metropolis, Washington, Brookings Institution Press.

Lynch, Kevin (1981), A Theory of Good City Form, Massachusetts, Massachusetts Institute of Technology Press.

Méndez, Ricardo (2007), "El territorio de las nuevas economías metropolitanas”, Eure, vol. 33, núm. 100, pp. 51-67. 
McMillen, Daniel (2003), "Employment Subcenters in Chicago: Past, Present and Future”, Economic Perspectives, vol. 27, núm. 2, pp. 2-14.

Nelson, Howard (1971), "The Form and Structure of Cities: Urban Growth Patterns", en Larry Bourne (coord.), Internal Structure of the City, Toronto, Oxford University Press, pp. 75-83.

Ó hUallacháin, Breandán y Timothy Leslie (2009), "Post-Industrial Manufacturing in a Sunbelt Metropolis: Where Are Factories Located in Phoenix?", Urban Geography, vol. 30, núm. 8, pp. 898-926.

Ramírez, Blanca (2006), "Del funcionalismo industrial al funcionalismo de servicios. ¿La nueva utopía de la metrópoli postindustrial del Valle de México?”, Eure, vol. 32, núm. 95, pp. 61-74.

Scott, Allen (1983), "Industrial Organization and the Logic of Intra-Metropolitan Location: Theoretical Considerations”, Economic Geography, vol. 59, núm. 3, pp. 223-250.

Shearmur, Richard y William Coffey (2002), "A Tale of Four Cities: Intrametropolitan Employment Distribution in Toronto, Montreal, Vancouver and Ottawa-Hull, 1981-1996”, Environment and Planning A, vol. 34, núm. 4, pp. 575-598.

Sobrino, Jaime (2006), "Macroestructuración espacial del sector servicios en la Ciudad de México", en Gustavo Garza (coord.), La organización espacial del sector servicios en México, México, El Colegio de México, pp. 425-455.

Yu-Hsin, Tsai (2005), “Quantifying Urban Form: Compactness versus 'Sprawl'”, Urban Studies, vol. 42, núm. 1, pp. 141-161.

Unikel, Luis, Crescencio Ruiz y Gustavo Garza (1976), El desarrollo urbano de México: diagnóstico e implicaciones futuras, México, El Colegio de México.

Veltz, Pierre (1999), Mundialización, ciudades y territorios: la economía de archipiélago, Barcelona, Ariel.

\section{Acerca de los autores}

Fermín Alí Cruz Muñoz es licenciado en Arquitectura y maestro en Urbanismo por la Facultad de Arquitectura de la Universidad Nacional Autónoma de México. Es doctor en Estudios Urbanos y Ambientales por el Colegio de México, institución donde obtuvo el Premio Gustavo Cabrera 2014 por el Mejor Trabajo de Investigación en Estudios Urbanos y Ambientales.

Actualmente es investigador asociado en el proyecto "Estructuración intrametropolitana del sector servicios en la Ciudad de México, 1960-2008", dirigido por el doctor Gustavo Garza, y es docente de la Facultad de Arquitectura de la Universidad Nacional Autónoma de México. 
Gustavo Garza es profesor investigador del Centro de Estudios Demográficos, Urbanos y Ambientales de El Colegio de México desde 1970. Ha publicado 232 artículos y capítulos de libro sobre desarrollo urbano en México en revistas y libros especializados y es autor de 28 obras sobre el tema, así como de dos planes estatales de desarrollo económico y urbano en Nuevo León y Tamaulipas. Ha sido investigador visitante en la Universidad de California; en el Centro Brasileño de Análisis y Planeación, en São Paulo, Brasil; en la Universidad de Texas, Austin; en la Universidad de Cambridge, Inglaterra; en la London School of Economics and Political Sciences, Inglaterra; y en la Universidad de Alcalá, España. Fue miembro del panel sobre Dinámica Urbana de la Academia Nacional de Ciencias de Estados Unidos de 1999 a 2003. Es Investigador Nacional Emérito.

Desde 2010 ha trabajado en la investigación "Estructuración intrametropolitana del sector servicios en la Ciudad de México, 1960-2008", de la cual ha derivado una trilogía de libros sobre el valor de la infraestructura y equipamiento de la urbe, a partir de lo que analizará la localización del sector comercio y servicios para intentar determinar el patrón que sigue su organización intrametropolitana y los factores que la determinan. 